\title{
Robotic observations of high wintertime carbon export in California coastal waters
}

\author{
James K. B. Bishop ${ }^{1,2}$, Michael B. Fong ${ }^{3}$, and Todd J. Wood ${ }^{2}$ \\ ${ }^{1}$ Department of Earth and Planetary Science, UC Berkeley, Berkeley, CA 94720, USA \\ ${ }^{2}$ Earth Sciences Division, Lawrence Berkeley National Laboratory, Berkeley, CA 94720, USA \\ ${ }^{3}$ Department of Chemistry, Scripps Institution of Oceanography, La Jolla, CA 92093, USA
}

Correspondence to: James K. B. Bishop (jkbishop@berkeley.edu)

Received: 22 February 2016 - Published in Biogeosciences Discuss.: 25 February 2016

Revised: 3 May 2016 - Accepted: 5 May 2016 - Published: 30 May 2016

\begin{abstract}
Biologically mediated particulate organic and inorganic carbon (POC and PIC) export from surface waters is the principal determinant of the vertical oceanic distribution of $\mathrm{pH}$ and dissolved inorganic carbon and thus sets the conditions for air-sea exchange of $\mathrm{CO}_{2}$; exported organic matter also provides the energy fueling communities in the mesopelagic zone. However, observations are temporally and spatially sparse. Here we report the first hourly-resolved optically quantified POC and PIC sedimentation rate time series from an autonomous Lagrangian Carbon Flux Explorer (CFE), which monitored particle flux using an imaging optical sedimentation recorder (OSR) at depths below $140 \mathrm{~m}$ in the Santa Cruz Basin, CA, in May 2012, and in January and March 2013. Highest POC vertical flux $(\sim 100$ $240 \mathrm{mmol} \mathrm{C} \mathrm{m}^{-2} \mathrm{~d}^{-1}$ ) occurred in January, when most settling material was millimeter- to centimeter-sized aggregates but when surface biomass was low; fluxes were $\sim 18$ and $\sim 6 \mathrm{mmol} \mathrm{C}^{-2} \mathrm{~d}^{-1}$, respectively, in March and May, under high surface biomass conditions. An unexpected discovery was that January 2013 fluxes measured by CFE were 20 times higher than that measured by simultaneously deployed surface-tethered OSR; multiple lines of evidence indicate strong undersampling of aggregates larger than $1 \mathrm{~mm}$ in the latter case. Furthermore, the January 2013 CFE fluxes were about 10 times higher than observed during multiyear sediment trap observations in the nearby Santa Barbara and San Pedro basins. The strength of carbon export in biologically dynamic California coastal waters is likely underestimated by at least a factor of 3 and at times by a factor of 20.
\end{abstract}

\section{Introduction}

Phytoplankton account for half of global net photosynthesis (Field et al., 1998), or about $50 \mathrm{PgC} \mathrm{yr}^{-1}$, yet they live for a week before being removed from the euphotic zone through grazing or abiotic aggregation processes. While most phytoplankton carbon is recycled in the surface layer, recent model- and observation-based estimates (Henson et al., 2011; Yao and Schlitzer, 2013; Siegel et al., 2014) suggest that globally 5 to $12 \mathrm{PgC} \mathrm{yr}^{-1}$ is exported below the euphotic zone as sinking particulate organic and inorganic carbon (POC and PIC) in fecal pellets, amorphous large aggregates, and independently sinking carapaces and calcareous shells (e.g., Bishop et al., 1978; Alldredge and Silver, 1988; Turner, 2015). Many large amorphous aggregate particles (e.g., greater in size than $0.5 \mathrm{~mm}$ ) would also be classified as marine snow by virtue of their being visible to the naked eye or camera in reflected light; such aggregates have been shown to originate as products of feeding (e.g., ejected boluses of fecal material, discarded mucus feeding webs, or appendicularian houses) or from turbulence-driven aggregation of biogenic organic and inorganic particles (Alldredge and Silver, 1988). Important to POC settling is particulate inorganic carbon (i.e., PIC), in the form of calcite foraminifera shells and coccolith plates and aragonite pteropod shells and shell fragments. Foraminifera shells preserved in sediments in particular are key to unraveling past climate and ocean chemistry, yet little of their dynamics in the water column has been understood (e.g., Bé et al., 1985). Together with siliceous diatom frustules and radiolarian tests, biogenic carbonates are a major factor governing the excess density, and hence sinking rate, of aggregate particles carrying POC downward from 
the surface layer (Armstrong et al., 2002). As much of the exported organic matter is consumed in the water column or at the sediment-sea-water interface, little POC is preserved in sediments. The varied processes of production, grazing, recycling, export, and subsurface remineralization constitute the ocean's biological carbon pump (Volk and Hoffert, 1985).

Direct observations of POC and PIC sedimentation fluxes in the upper thousand meters of the ocean are sparse, of short duration (days), and, with few exceptions, mostly during summertime. This is because all observations to date have required ships to be present or nearby (e.g., Martin et al., 1987; Buesseler et al., 2000; Stanley et al., 2004; Lam and Bishop, 2007; Lampitt et al., 2008; Lee et al., 2009; Owens et al., 2013).

Such direct observations are often used to calibrate models used to estimate global carbon export (e.g., Henson et al., 2011; Siegel et al., 2014). Henson et al. (2011) estimated an export of $5 \mathrm{PgC} \mathrm{yr}^{-1}$, based on the synthesis of a decade of ship observations of the ratio of dissolved radioactive ${ }^{234} \mathrm{Th}$ to parent ${ }^{238} \mathrm{U},{ }^{234} \mathrm{Th} / \mathrm{POC}$ ratios measured in shallow sediment trap or pump-sampled particulates, and satellite-based estimates of primary productivity. Siegel et al. (2014) estimated a global carbon export of $6 \mathrm{PgC}^{-1}$ using the combination of food web models - calibrated with shipboard observations of production, grazing, and sedimentation - and global satellite retrievals of size-dependent phytoplankton biomass. In contrast, Yao and Schlitzer (2013) estimated an export of $12 \mathrm{Pg} \mathrm{C} \mathrm{yr}^{-1}$ by inversion, within an ocean circulation model, of ocean nutrient fields averaged over 5 to 6 decades. It is unknown whether the factor of 2 difference in export numbers is a reflection of a strong, recently weakening biological carbon pump or of differences in methodology. Either way, there is major uncertainty in both the strength and stability of the ocean's biological carbon pump and of consequent feedbacks to atmospheric $\mathrm{CO}_{2}$ trends; furthermore, there remains major uncertainty as to the magnitude of the energy flow carried by sinking particles to sustain mesopelagic communities (Burd et al., 2010; Banse, 2013).

Eppley and Peterson (1979) pointed out the importance of nearshore waters, defined as coastal waters deeper than $200 \mathrm{~m}$, to the ocean carbon cycle. In their estimate, nearshore waters account for over $40 \%$ of global new production and hence particle export. While there have been arguments that this number may be somewhat high in the modern context (Henson et al., 2011), all recent calculations of global export (although not broken down as done as in Eppley and Peterson, 1979) indicate a lower contribution from coastal waters.

In this paper, we describe direct in situ observations of carbon export in biologically dynamic ocean waters near the California coast obtained using a fully autonomous ocean profiling Carbon Flux Explorer (CFE; Fig. 1a) that we have developed. The Carbon Flux Explorer is designed to perform sustained high-frequency observations of POC and PIC sedimentation within the upper kilometer (or twilight zone) of the ocean for seasons to years and to operate in an ob-

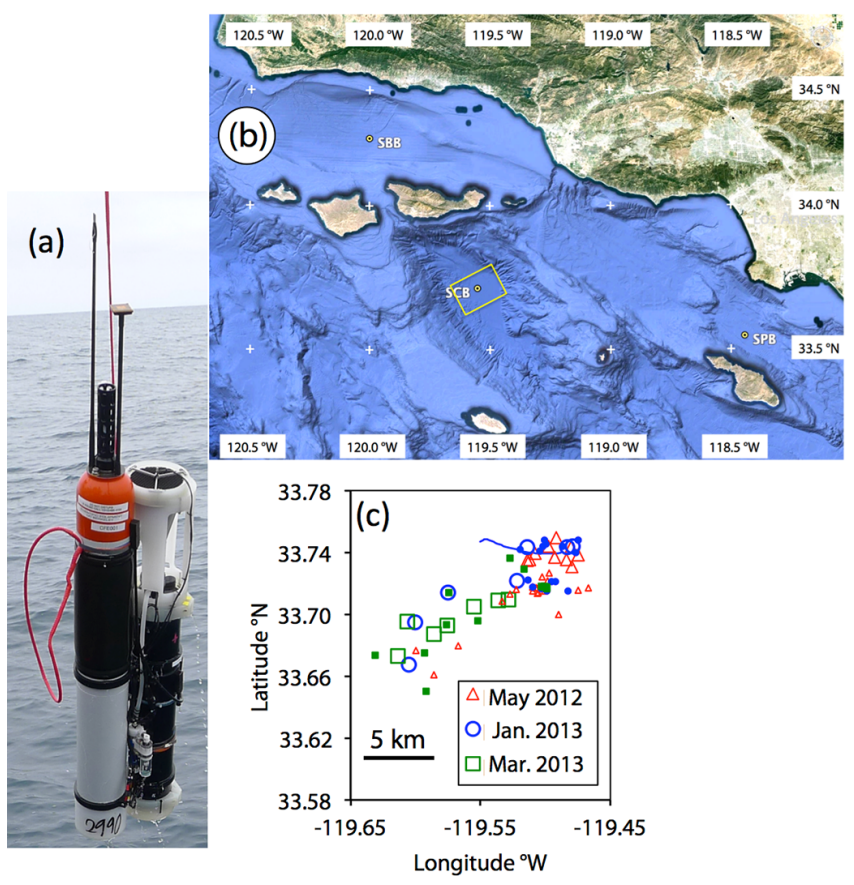

Figure 1. Left: Carbon Flux Explorer showing the Sounding Oceanographic Lagrangian Observer (SOLO) float and interfaced optical sedimentation recorder (OSR). Top right: relief map for Southern California Bight (Google Earth) centered on the Santa Cruz Basin (SCB) and our study area (shown in yellow). Also shown are locations of moored sediment trap deployments in the Santa Barbara Basin (SBB; Thunnel, 1998) and San Pedro Basin (SPB; Collins et al., 2011). Lower right: operations within study area. Surfacing positions of CFE001 during May 2012 (red triangles), January 2013 (blue circles), and March 2013 (green box); also shown is track for the surface-tethered OSR (BUOY-OSR) system (blue line) in January 2013; separation of CFE and BUOY-OSR was approximately $9 \mathrm{~km}$. Small symbols denote locations of conductivity, temperature, depth (CTD) rosette casts. All motion was to the southwest. CFE and BUOY-OSR deployments took place near $33.75^{\circ} \mathrm{N}, 119.5^{\circ} \mathrm{W}$. CTD rosette profiles were taken within several kilometers of CFE and BUOY-OSR positions.

servational context not dependent on ships. The CFE melds the concept of current-following, sample-collecting neutrally buoyant sediment traps (Buesseler et al., 2000; Stanley et al., 2004; Lampitt et al., 2008; Owens et al., 2013) with photographic imaging of the particles as they are deposited in a sediment trap (Asper, 1987). The current-following approach aims to avoid the hydrodynamic biases likely with surface-tethered sediment traps (Gardner, 2000; Buesseler et al., 2007).

Bishop et al. (2004), Bishop and Wood (2009) and Estapa et al. (2013) have deployed transmissometer-equipped profiling floats to observe the high-frequency variability of the systematics of sedimentation. When the floats yo-yo from depth to the surface, transmissometers record the concentration variability of particles in the water column. As the floats 
drift at depth between profiles, there is a measurable transmission loss (or attenuance increase) as settled particles accumulate on the upward-looking transmissometer window. These data, when normalized by the time at depth, yield a simple metric, or index, of sedimentation. In contrast, with direct high-resolution imaging of the settled particles, the CFE is not only able to quantify optical metrics of particle flux but is also able to gain detail on the kinds of particles and thus the specifics of the process governing carbon export.

Below, we present observations from CFE development testing during three expeditions off the coast of southern California aboard R/V New Horizon: 29 May-4 June 2012 (NH1204), 18-21 January 2013 (NH1301), and 27-31 March 2013 (NH1304). These observations, like past shiptended studies using neutrally buoyant and surface-tethered sediment traps, are of relatively short duration (days); however, they are the first carried out in a productive coastal environment. CFE data are analyzed below in the framework of remotely sensed surface chlorophyll and POC, in situ water column optical properties, and subsurface currents. The study site is a $150 \mathrm{~km}^{2}$ region centered at $33^{\circ} 43^{\prime} \mathrm{N}$, $119^{\circ} 33^{\prime} \mathrm{W}$ in the $1900 \mathrm{~m}$ deep Santa Cruz Basin (SCB) near the California coast (Fig. $1 \mathrm{~b}$ and c).

\section{Methods}

\subsection{Carbon Flux Explorer (CFE) and surface-tethered OSR (BUOY-OSR)}

The CFE is comprised of an optical sedimentation recorder (OSR) interfaced with a conductivity-temperature-depth (CTD) equipped Sounding Oceanographic Lagrangian Observer (SOLO) float (Davis et al., 2001). The CFE dives repeatedly (daily in this study) below the surface to obtain OSR observations at three target depths. The CFE's optical sedimentation recorder (OSR; Fig. A1, Sect. A1 in the Appendix) awakes when the CFE reaches a target depth. Particles settle through a hexagonal celled baffle $(1 \mathrm{~cm}$ opening, $5 \mathrm{~cm}$ length) into a high-aspect titanium funnel and settling column before depositing on a $2.54 \mathrm{~cm}$ diameter glass sample stage; the funnel diameter is $15.4 \mathrm{~cm}$. Particles are imaged in three lighting modes: transmitted, transmitted-crosspolarized, and dark field. On first wake-up of a given dive, the sample stage is flushed with water and images of the particle-free stage are obtained. At timed intervals $(\sim 20 \mathrm{~min}$ in data described here) the OSR repeats image sets, which register the sequential buildup of particles. After the predetermined number of image sets over $\sim 1.8 \mathrm{~h}$, cleaning occurs and a new reference image set is obtained. After $\sim 5 \mathrm{~h}$ at a target depth, the OSR performs a final image and cleaning cycle and reference image set, and the SOLO surfaces to report GPS position, CTD profile data and OSR engineering data, and dives to its next target depth (Table 1). Every three
Table 1. Carbon Flux Explorer and BUOY-OSR positions.

\begin{tabular}{|c|c|c|c|c|}
\hline \multirow[b]{2}{*}{ Dive } & \multicolumn{4}{|c|}{ Carbon Flux Explorer surfacing positions } \\
\hline & Date & Time (UTC) & Longitude & Latitude \\
\hline 123 & 1-Jun-2012 & $3: 15$ & -119.475 & 33.738 \\
\hline 124 & 1-Jun-2012 & $11: 49$ & -119.479 & 33.731 \\
\hline 125 & 1-Jun-2012 & $21: 14$ & -119.484 & 33.736 \\
\hline 126 & 2-Jun-2012 & $4: 52$ & -119.480 & 33.744 \\
\hline 127 & 2-Jun-2012 & $13: 28$ & -119.498 & 33.744 \\
\hline 128 & 2-Jun-2012 & $22: 48$ & -119.492 & 33.750 \\
\hline 129 & 3-Jun-2012 & $6: 24$ & -119.493 & 33.737 \\
\hline 130 & 3-Jun-2012 & $15: 10$ & -119.508 & 33.740 \\
\hline 131 & 3-Jun-2012 & $20: 45$ & -119.512 & 33.735 \\
\hline 143 & 19-Jan-2013 & $8: 16$ & -119.479 & 33.744 \\
\hline 144 & 19-Jan-2013 & $9: 13$ & -119.484 & 33.744 \\
\hline 145 & 19-Jan-2013 & $16: 31$ & -119.514 & 33.744 \\
\hline 146 & 19-Jan-2013 & $23: 45$ & -119.522 & 33.722 \\
\hline 147 & 20-Jan-2013 & $8: 21$ & -119.575 & 33.714 \\
\hline 148 & 20-Jan-2013 & $14: 52$ & -119.600 & 33.695 \\
\hline 149 & 20-Jan-2013 & $20: 46$ & -119.605 & 33.667 \\
\hline 161 & 28-Mar-2013 & $10: 55$ & -119.537 & 33.709 \\
\hline 162 & 28-Mar-2013 & $18: 19$ & -119.529 & 33.709 \\
\hline 163 & 29-Mar-2013 & 4:08 & -119.555 & 33.705 \\
\hline 164 & 29-Mar-2013 & $10: 47$ & -119.586 & 33.687 \\
\hline 165 & 29-Mar-2013 & $18: 05$ & -119.576 & 33.693 \\
\hline 166 & 30-Mar-2013 & $3: 02$ & -119.607 & 33.696 \\
\hline \multirow[t]{18}{*}{167} & 30-Mar-2013 & $9: 46$ & -119.614 & 33.673 \\
\hline & \multicolumn{4}{|c|}{ BUOY-OSR positions January 2013} \\
\hline & Date & Time (UTC) & Longitude & Latitude \\
\hline & 20-Jan-2013 & 9:00 & -119.490 & 33.740 \\
\hline & 20-Jan-2013 & $10: 00$ & -119.496 & 33.739 \\
\hline & 20-Jan-2013 & 11:00 & -119.501 & 33.739 \\
\hline & 20-Jan-2013 & $12: 00$ & -119.507 & 33.739 \\
\hline & 20-Jan-2013 & 13:00 & -119.513 & 33.740 \\
\hline & 20-Jan-2013 & $14: 00$ & -119.519 & 33.741 \\
\hline & 20-Jan-2013 & $15: 00$ & -119.524 & 33.742 \\
\hline & 20-Jan-2013 & $16: 00$ & -119.530 & 33.744 \\
\hline & 20-Jan-2013 & 17:00 & -119.534 & 33.745 \\
\hline & 20-Jan-2013 & 18:00 & -119.538 & 33.746 \\
\hline & 20-Jan-2013 & $19: 00$ & -119.542 & 33.747 \\
\hline & 20-Jan-2013 & 20:00 & -119.545 & 33.748 \\
\hline & 20-Jan-2013 & 21:00 & -119.546 & 33.749 \\
\hline & 20-Jan-2013 & 22:00 & -119.548 & 33.748 \\
\hline & 20-Jan-2013 & 23:00 & -119.550 & 33.747 \\
\hline
\end{tabular}

dive cycles, the depth order is repeated; in the current study, target depths were 150,300 , and $500 \mathrm{~m}$. A ballasting error in May 2012 led to the CFE operating 300 to $400 \mathrm{~m}$ deeper than planned. In the CFE described here, all images were stored aboard the OSR for post recovery analysis.

We also deployed an OSR tethered at $237 \mathrm{~m}$ below a drifting buoy array in January 2013. This system is referred to as BUOY-OSR in the text. Positions of CFE surfacing and of the surface-tethered BUOY-OSR are summarized in Table 1. 


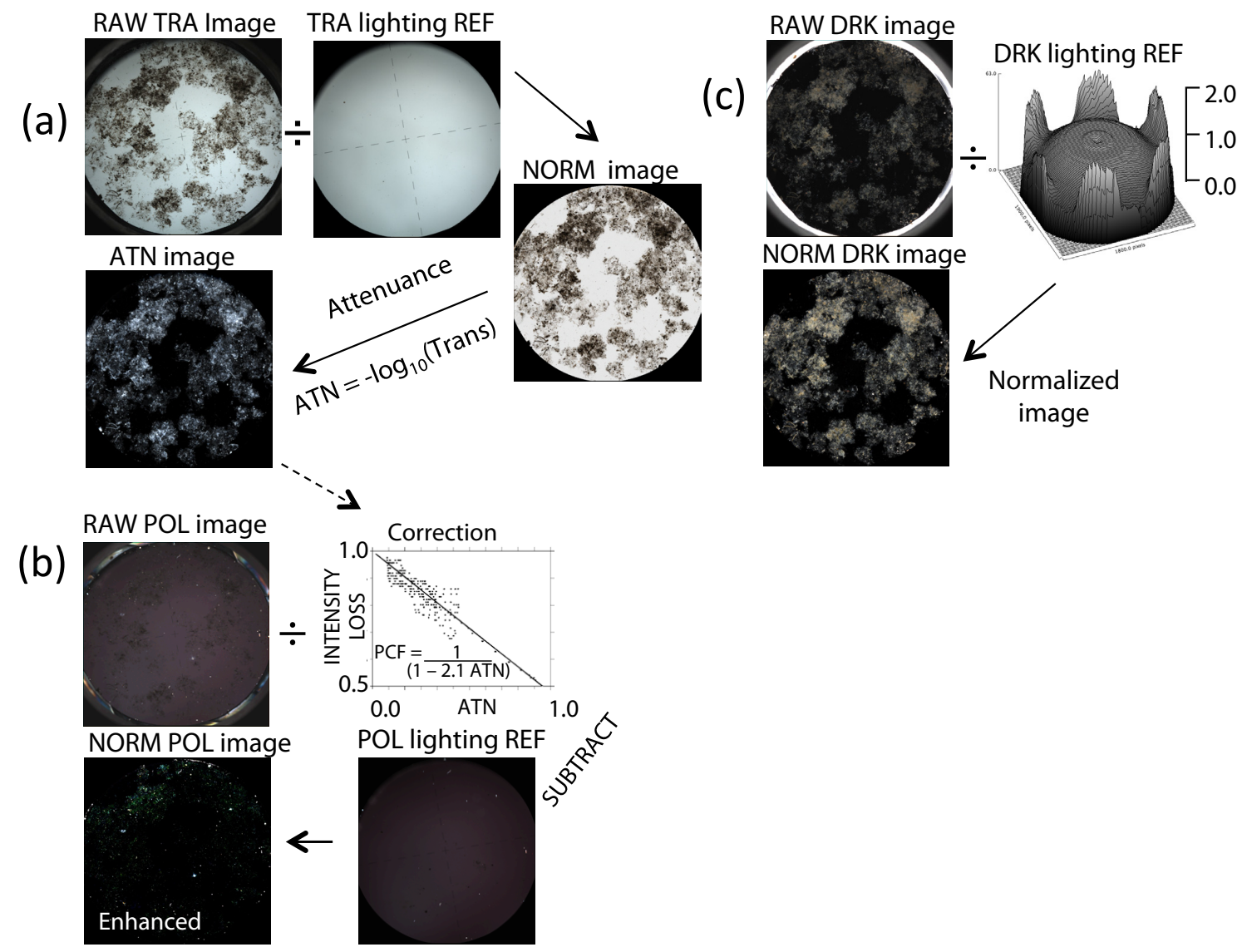

Figure 2. Detail of image analysis scheme for CFE and BUOY-OSR images. Images from NH1301 CFE001 deployment. Panel (a): raw backlit (TRA) images are divided by the in situ TRA lighting reference (cross-hair reticle has $1 \mathrm{~mm}$ sized dashes) to get transmittance. This image is transformed to units of attenuance. Panel (b): raw crossed polarized transmitted light (POL) image is first corrected for attenuation effects of optically dense particles by dividing by PCF, an empirically derived factor proportional to attenuance (ATN). The POL lighting REF is then subtracted and intensity normalized by the TRA lighting REF to yield the NORM POL image. The contrast and brightness of the final image is enhanced. Panel (c): raw dark field (DRK) images are normalized by dividing by the in situ lighting reference intensity.
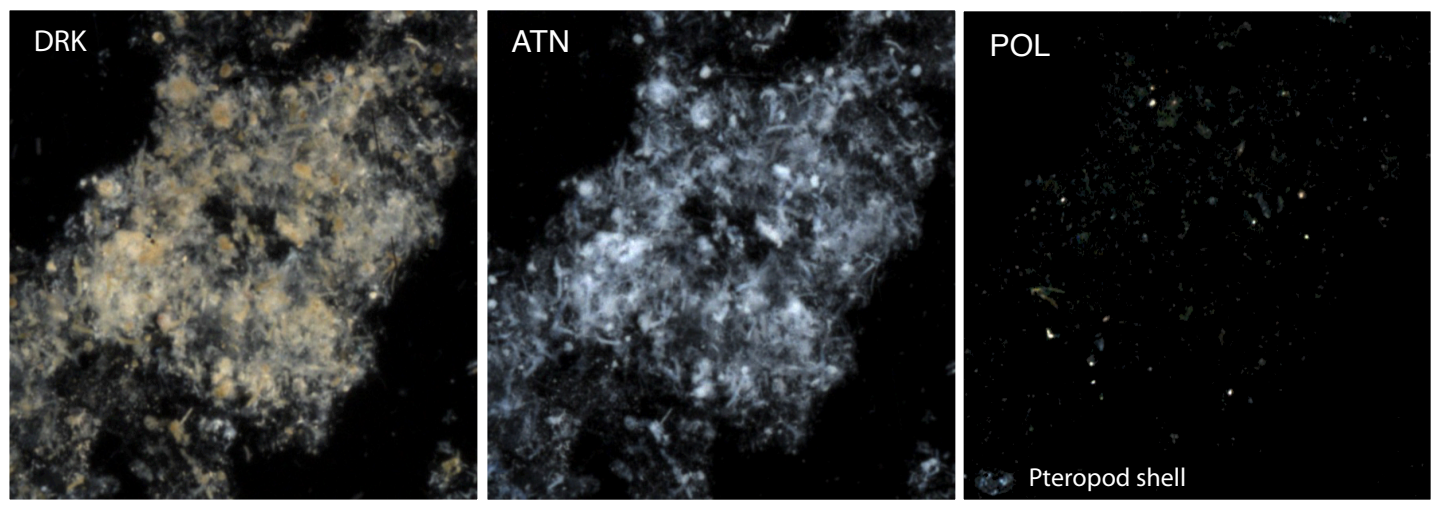

Figure 3. Magnified detail of a marine-snow aggregate from the upper left-hand quadrant of the sample image in Fig. 2 after processing to normalized dark field (DRK) counts, attenuance (ATN), and polarized (POL) counts. The scale of the aggregate is $\sim 1 \mathrm{~cm}$. Image resolution is $13 \mu \mathrm{m}$. An empty $600 \mu \mathrm{m}$ pteropod shell is at the bottom left of the POL image. The 10 bright spherical regions in the POL image are $\sim 200 \mu \mathrm{m}$ sized foraminifera shells; haze in aggregates is likely due to coccoliths. 


\subsection{OSR image data reduction}

Images were taken under transmitted, transmitted-crosspolarized, and dark field illumination and were processed to yield three parameters that characterize particle abundance, according to the scheme depicted in Fig. 2. The parameters are particle attenuance, cross-polarized photon yield, and dark field counts. Attenuance is the best measure of particle loading as light is reduced exponentially as it propagates through the sample. Cross-polarized photon yield takes advantage of the birefringent property of calcium carbonate and is a measure of particulate inorganic carbon. Dark field counts reveal the color of particles. Details of the treatment of transmitted light and transmitted cross-polarized light images are covered in Sects. 2.2.1 and 2.2.2, respectively. Dark field images are normalized by illumination intensity and then transformed to a consistently scaled reflectance in counts above background. A full-resolution post-processing image of an aggregate particle from January 2013 is shown for all modes of illumination in Fig. 3.

\subsubsection{Attenuance (ATN)}

Transmitted light (TRA) images are normalized by an in situ particle-free image of the sample stage area under transmitted light illumination. Image attenuance (ATN), the sum of both light scattering loss and particle absorption of the primary beam, is calculated as the negative $\log _{10}$ of transmittance and is a measure of both aggregate thickness and transparency. The effects of overlaying particles are additive in attenuance units. We calculate attenuance in $\log _{10}$ units rather than in natural log units as order-of-magnitude changes of transmission are easy to infer. Attenuance data reported here may be converted to natural $\log$ units by multiplying by 2.303.

In order to detect particles, we set the lowest threshold of pixel attenuance to be 0.02 . The attenuance of all pixels identified as particles is integrated across sample stage area and then divided by the total number of pixels of the sample stage area to yield the average particle load of the sample stage (in attenuance units). For convenience, attenuance is multiplied by 1000 and reported in units of milli-attenuance (mATN, Fig. 4a). The stage load, when multiplied by sample stage area, yields units of $\mathrm{mATN} \mathrm{\textrm {cm } ^ { 2 }}$. Because the light source is directly above the sample stage, the stage load $\left(\mathrm{mATN} \mathrm{cm}^{2}\right)$ is an optical "volume" of material on the sample stage. Attenuance flux (in units of mATN cm $\mathrm{cm}^{-2} \mathrm{~d}^{-1}$ ) is calculated by taking differences of successive stage loads, divided by the mouth opening of the trap, and further divided by the time (in days) between image sets (Fig. 5a). Attenuance is never saturated in our images (e.g., transmission is always greater than 0).

\subsubsection{Cross-polarized photon yield (POL)}

Transmitted, cross-polarized light images are processed in three steps: compensation for the attenuation effects of particles, subtraction of the particle-free blank and normalization for light source intensity. Due to the isolation of substage polarizer in the pressure case of the OSR, hydrostatically induced stress on the glass pressure case window at depth induces an interference seen by the camera; thus, absorbing particles appear dark in the uncorrected image (Fig. $2 \mathrm{~b}$ - RAW POL image). The absorption effect is compensated by the division of observed image counts by a polarization compensation factor (PCF), an empirically derived function of attenuance: $\mathrm{PCF}=1 /(2.1 \times \mathrm{ATN})$. This stress polarization interference has been eliminated in later builds of the CFE by moving the substage polarizer outside of the pressure case.

Following correction, image counts at each pixel (for particles identified using the 0.02 attenuance threshold) are integrated across all particle pixels and normalized by the total number of pixels covering the stage area. Sample counts are normalized to lamp brightness and scaled by the difference in exposure time for POL vs. TRA images to yield the quantity cross-polarized photon yield, expressed as a fraction of incident beam intensity. Results are scaled up by $10^{6}$ and data are reported in parts per million (Fig. 4b). This optical measure of flux is in units of $\mathrm{ppm} \mathrm{cm}^{2} \mathrm{~cm}^{-2} \mathrm{~d}^{-1}$ (Fig. 5b).

\subsubsection{Interference by swimmers}

In the PIC flux time series, there were several instances when a calcified swimming organism was detected. This mainly affected data from expedition NH1304, and cyprid barnacle larvae were the predominant interfering organism. When the appearance and disappearance of these organisms in the image series led to a strong positive and then negative flux, the interfering flux estimate was eliminated from the $1.8 \mathrm{~h}$ average. In one other case during NH1304, a calcified amphipod carapace (Fig. 4b) was removed from the $1.8 \mathrm{~h}$ average PIC flux. This carapace was clearly part of the flux but was excluded in our consideration of aggregate sedimentation. Excluded points in Fig. $5 \mathrm{~b}$ are indicated by circled $(\oplus)$ symbols. Attenuance flux data were not modified as swimmer interference did not alter the signal in a dominant way.

\subsubsection{POC and PIC flux proxy}

We hypothesize that attenuance is the best proxy for the POC in particles by analogy to the finding that the transmissometer measured particle beam attenuation coefficient $\left(c_{\mathrm{P}}\right)$ is highly correlated to POC concentration (e.g., Bishop and Wood, 2008). We note that the particle beam attenuation coefficient is expressed in units of per meter, while our attenuance values are dimensionless. This is because in transmissometry, beam attenuation occurs continuously along the seawater path that the light beam passes through. In our case, the path length 
(a)
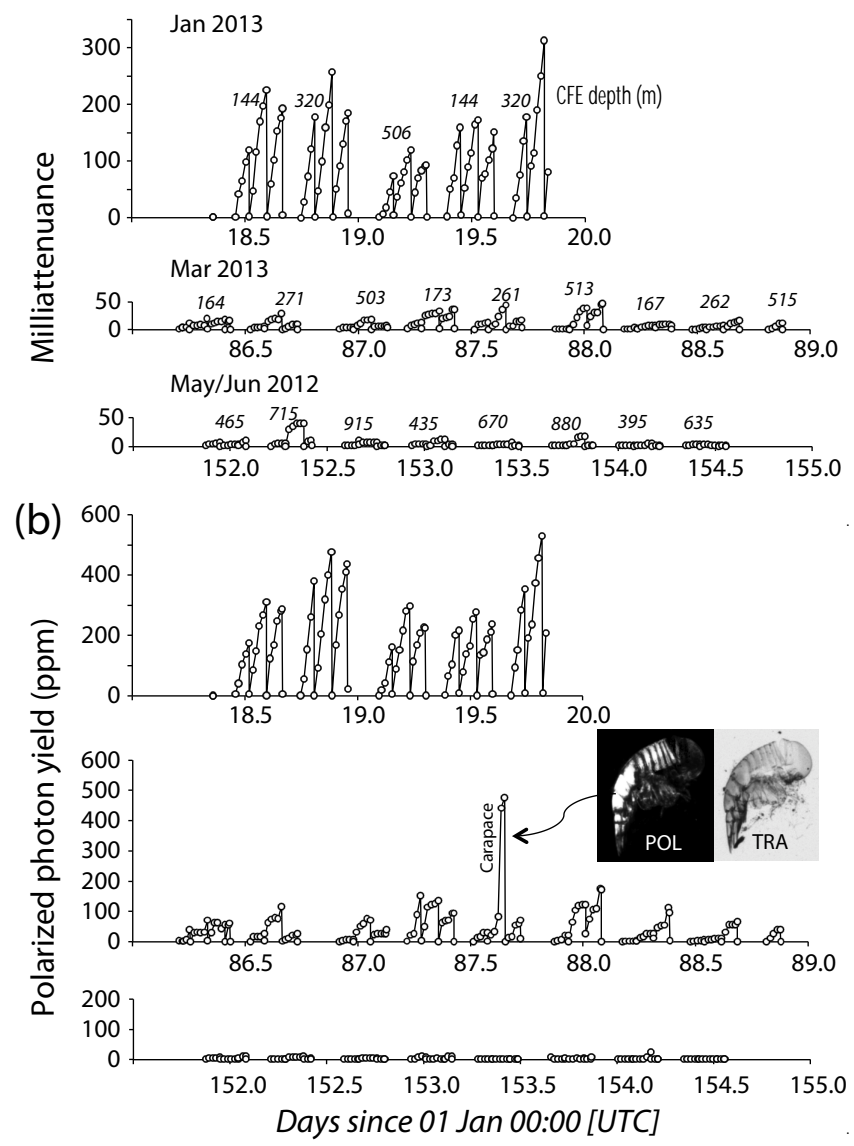

Figure 4. Results from CFE deployments in the Santa Cruz Basin. CFE depths shown in italics. Panel (a): sample attenuance from transmitted light images. Panel (b): polarized photon yield in parts per million from cross-polarized light images. Small circles denote the time that the images were taken. The sawtooth pattern registers particle accumulation and drops to baseline at the time of stage cleaning.

from light to sample stage is unimportant as all attenuance of light occurs in the thin layer of particles on the sample stage. Our use of the image of the light source as a transmission reference removes the minor effects of light loss through the water path.

Cross-polarized photon yield is a measure of PIC, which is comprised of biogenic calcite and aragonite polymorphs of calcium carbonate. The photon yield under cross-polarized illumination (or birefringence) of carbonates has been shown to scale linearly with PIC concentration; furthermore, biogenic carbonates both dominate all mineral material in the water column and have a 10 times greater photon yield compared with other birefringent minerals (Guay and Bishop, 2002).

\subsection{Conversion of $\mathrm{POC}_{\mathrm{ATN}}$ flux to POC flux}

Calibration samples from the BUOY-OSR system were not useful due to a 20-fold lower particle collection rate compared to that of the CFE (described below in Sect. 3.3). We thus estimate the amount of POC in our images in order to translate attenuance flux to POC flux.

Bishop et al. (1978) report information on the dry-weight density and geometric properties of particles of similar morphology as sampled here. Particularly, we use a particle dryweight density of $0.087 \mathrm{~g} \mathrm{~cm}^{-3}$, and the Bishop et al. (1978) equation, which estimates aggregate thickness $(h$, in $\mathrm{cm})$ as a function of equivalent circular diameter $(d$, in $\mathrm{cm})$ :

$h=0.052 d+0.0045$.

We analyzed a series of five images collected on 20 January 2013 from 11:11:47 to 12:39:47 UTC (just before cleaning). The last image of this set had $65 \%$ of the sample stage covered with particles. These images are provided in the Supplement for readers to independently analyze. The software package ImageJ (National Institutes of Health, USA http://rsb.info.nih.gov/ij) was used to measure the equivalent circular diameter of aggregates. As aggregates overlapped in successive images due to the unexpectedly high sedimentation observed, successive images were stepwise subtracted in pairs prior to size analysis. Aggregate volume was calculated as the product of cross sectional area and thickness, $\mathrm{h}$.

A total of 127 aggregates from $500 \mu \mathrm{m}$ to $8.3 \mathrm{~mm}$ in size were enumerated in all five images. A size cutoff of $800 \mu \mathrm{m}$ was used to minimize contamination of the analysis due to the slight expansion of aggregate dimension over time as they rested on the stage. Although size distributions were initially quantified to a lower limit of $20 \mu \mathrm{m}$, it is important to note that $97 \%$ of the volume attenuance of the sample was accounted for by particles $>800 \mu \mathrm{m}$ in this sample. For the remaining 63 particles larger than $800 \mu \mathrm{m}$, we calculated an aggregate volume of $0.113 \mathrm{~cm}^{3}$. To estimate the POC flux, we assume an aggregate dry-weight density of $0.087 \mathrm{~g} \mathrm{~cm}^{3}$ (e.g., from Fig. 22 in Bishop et al., 1978) and thus calculate the weight of aggregate matter as $0.0098 \mathrm{~g}$. Organic matter at depths between 100 and $500 \mathrm{~m}$ is typically $60 \%$ (range $50-70 \%$ ) of dry weight (Fig. 11 in Bishop et al., 1978). Thus, organic-matter $(\mathrm{OM})$ weight is $0.0059 \mathrm{~g}$. We estimate POC (as carbon) by dividing this mass by the $\mathrm{OM}: \mathrm{C}$ conversion factor, 1.88 from Hedges et al. (2002). We divide by 12.011, the atomic weight of carbon, to yield a POC loading of $0.26 \times 10^{-3}$ moles. The opening of the OSR funnel has a diameter of $15.4 \mathrm{~cm}$, which yields an assumed trap collection area of $186.3 \mathrm{~cm}^{2}$. The time interval for collection of this sample was $1.84 \mathrm{~h}$, or 0.0766 days. Combining this information yields a carbon flux of $183 \mathrm{mmol} \mathrm{m}^{-2} \mathrm{~d}^{-1}$. The average POC $_{\text {ATN }}$ flux for all particles $>13 \mu \mathrm{m}$ in size during the same time interval was $66.2 \mathrm{mATN} \mathrm{cm}^{2} \mathrm{~cm}^{-2} \mathrm{~d}^{-1}$. As mentioned above, over $97 \%$ of cumulative sample attenuance was in the $>800 \mu \mathrm{m}$ size fraction. The conversion factor for $\mathrm{POC}_{\mathrm{ATN}}$ 

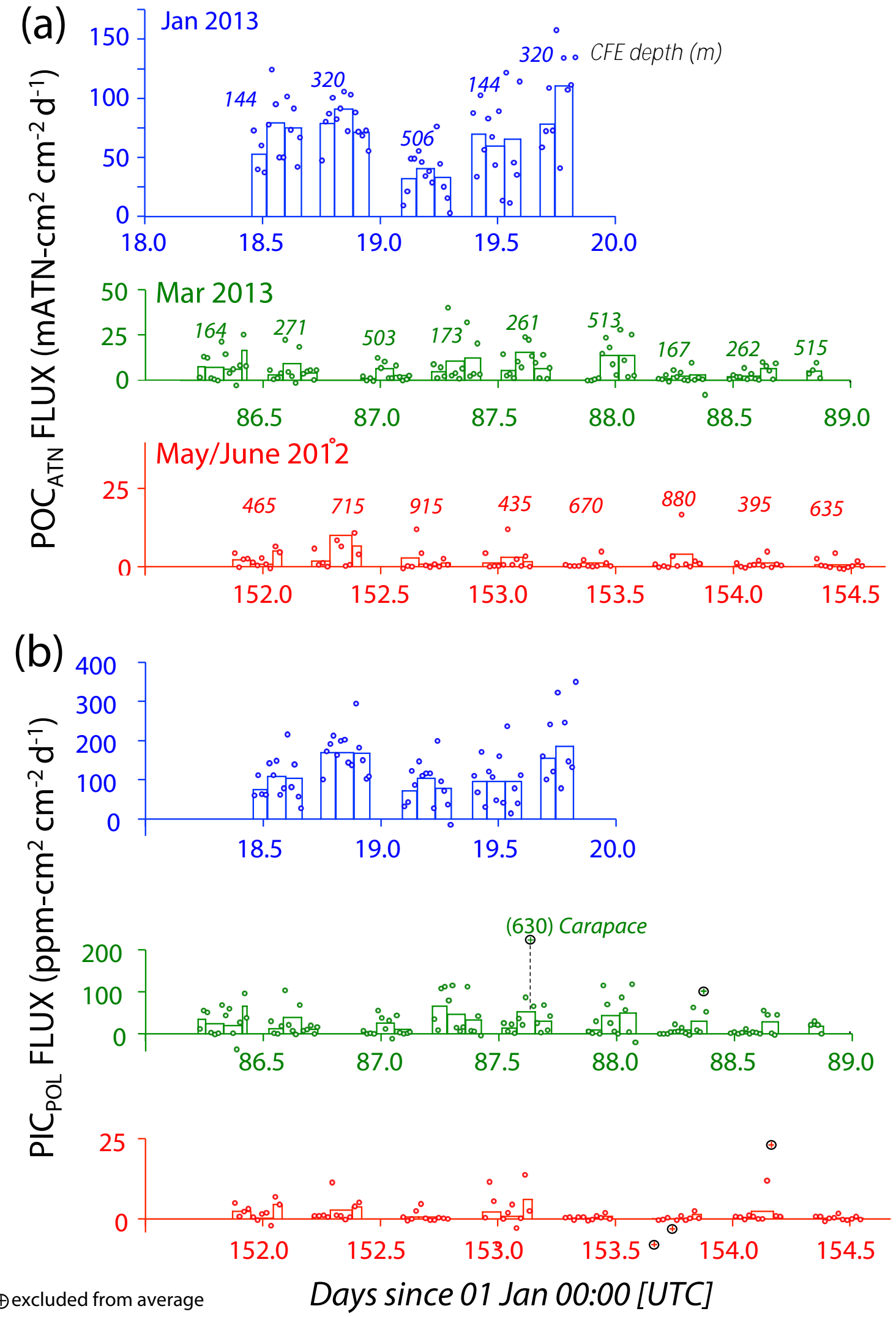

Figure 5. $\mathrm{POC}_{\mathrm{ATN}}$ (a) and $\mathrm{PIC}_{\mathrm{POL}}$ (b) flux systematics from CFE deployments in the Santa Cruz Basin. CFE depths are shown in italics in (a). Bars and small circles denote average flux over 1.8 and $0.3 \mathrm{~h}$ intervals, respectively. 
flux to POC flux is the ratio of 183 to $66.2 \times 0.97=2.8$. This conversion factor allows the estimation of POC fluxes observed for a comparison with other data from nearby waters.

Alldredge (1998) collected marine snow using scuba at euphotic depths of 10 to $20 \mathrm{~m}$ in the nearby Santa Barbara Basin. They imaged particles in the laboratory, derived maximum and minimum dimensions, and assumed an elliptical volume. From this they calculated the equivalent spherical volume (ESV in $\mathrm{mm}^{3}$ ). Samples were analyzed for POC and a regression formula was derived (POC $\left.(\mu \mathrm{g})=0.99 \times \mathrm{ESV}^{0.52}\right)$. If we use the ImageJ 2-D analyses of minimum and maximum aggregate dimensions in our images to compute ESV following Alldredge's methods, we get a summed ESV value that is 8.5 times higher than that obtained using our approach. If we use the Alldredge (1998) conversion of ESV to POC for each aggregate and sum over all particles $>1 \mathrm{~mm}$ in size, then the amount of POC is 17 times lower than our estimate. The Alldredge method yields a POC density for aggregates equal to $0.00020 \mathrm{~g} \mathrm{C} \mathrm{cm}^{-3}$, while our method yields $\sim 0.028 \mathrm{~g} \mathrm{C} \mathrm{cm}^{-3}$. The carbon density of aggregate particles derived from their equations differs from ours by a factor of 140 . We are not sure if the marine-snow particles sampled by Alldredge (1998) in shallow waters were mostly empty of material, or if they deflate as they sink below the euphotic zone. Bishop et al. (1978) describe aggregates sampled from 100-400 $\mathrm{m}$ that appeared similarly loaded to those described here; for this reason believe that our method is internally most consistent.

We stress that the factor 2.8 used for the conversion of $\mathrm{POC}_{\mathrm{ATN}}$ flux to POC flux is approximate. Equation (1) for aggregate thickness is the only applicable published study that we are aware of. The dry-weight density factor $\left(0.087 \mathrm{~g} \mathrm{~cm}^{-3}\right)$ was taken for aggregates that were similarly optically dense as observed in this sample. Bishop et al. (1978) also reported dry density values as high as $0.24 \mathrm{~g} \mathrm{~cm}^{-3}$. The organic-matter percentage for large particulates used in the calculation above is typical of values obtained by our group using in situ filtration. We note that Collins et al. (2011) report upper water column POC flux and mass flux data from surface-tethered sediment traps in the San Pedro Basin (Fig. 1), closer to the shore, which yield OM values closer to $30 \%$, with the rest being contributed by inorganic terrigenous and biogenic phases. This would require our estimate of dry-weight particle density to be proportionately adjusted upwards to account for the greater fraction of inorganic ballasting material and thus compensate for the reduced organic percentage. A factor of 2 adjustment of the POC : POC $_{\text {ATN }}$ ratio either way will not change our conclusions regarding the high magnitude of the sedimentation rate observed in January 2013 by the CFE, nor will it change the relative difference observed between CFE and BUOY-OSR presented below.

\subsection{Satellite data processing}

Retrievals of chlorophyll and POC from observations made by the Moderate Resolution Imaging Spectroradiometer (MODIS) on NASA's Aqua satellite are provided on the NASA Distributed Active Archive Center (DAAC). Level 2 Local Area Coverage (L2-LAC) data at $1 \mathrm{~km}$ resolution for the period of the three expeditions were downloaded on April 42013 and processed using SeaDAS software. Chlorophyll and POC were retrieved for pixels within a $2 \mathrm{~km}$ search radius of $33.72^{\circ} \mathrm{N}, 119.5^{\circ} \mathrm{W}$ and were selected using the standard ocean color processing quality flags. Means and standard deviations were calculated and data were further selected based on the requirement of five valid pixels. Further analysis of spatial and temporal trends of chlorophyll within our study area is presented in Appendix Sect. A3.

Surface photosynthetically active radiation (PAR) estimated from MODIS Aqua data for January, March, and May expeditions was 25,45 , and 60 einsteins $\mathrm{m}^{-2} \mathrm{~d}^{-1}$, respectively. Corresponding values for diffuse attenuation coefficient for PAR $\left(k_{\mathrm{PAR}}\right)$ from beam attenuation coefficient profiles (Bishop and Wood, 2009) were 0.068, 0.20, and $0.18 \mathrm{~m}^{-1}$. Euphotic zone depths corresponding to the $1 \%$ light level were 68,23 , and $26 \mathrm{~m}$. The euphotic zone depths based on the $1 \mathrm{E} \mathrm{m}^{-2} \mathrm{~d}^{-1}$ isolume were 50,20 , and $25 \mathrm{~m}$.

\section{Results}

\subsection{Flux time series, hydrography, and remote sensing data}

Figure 5 (above) shows the time series of $\mathrm{POC}_{\mathrm{ATN}}$ flux and PIC $_{\mathrm{POL}}$ flux. In contrast to surface-tethered sediment traps (Martin et al., 1987), we found that the influence by/presence of swimming organisms was rarely significant in our image time series (see Supplement animations of CFE imagery). The highest POC $_{\text {ATN }}$ flux was measured in January 2013, intermediate flux was observed in March 2013, and lowest flux was observed in May 2012. Similar temporal-depth systematics were observed for $\mathrm{PIC}_{\mathrm{POL}}$ flux (Fig. 5b); however, the relative ratio of PIC / POC flux was highest in March 2013.

The hydrographic context for our observations was established by CTD and transmissometer casts made to full water depth three to four times per day during each expedition. We found that mixed layer depths were mostly shallower than $10 \mathrm{~m}$ during all expeditions, reflective of the California coastal upwelling regime and net divergence of surface waters in the Santa Cruz Basin. We calculate properties of the upper $20 \mathrm{~m}$, as these are most closely comparable to remotely sensed surface properties. Upper $20 \mathrm{~m}$ temperatures for January, March, and May averaged 12.6, 13.5, and $15{ }^{\circ} \mathrm{C}$, respectively, reflecting seasonal warming. Over each cruise, averaged 0-20 m POC concentrations derived from transmissometer profiles $( \pm \mathrm{SD}$; Appendix Sect. A2; 


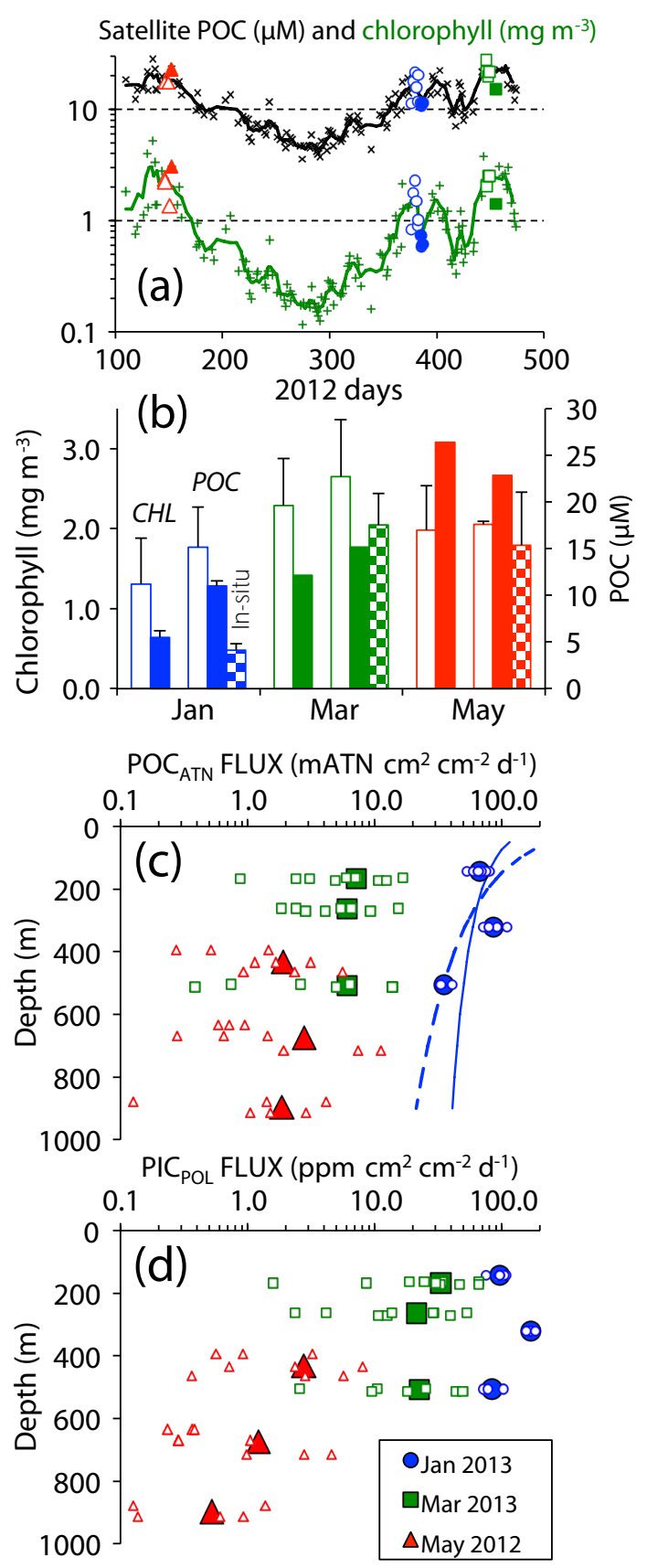

Figure 6. Panel (a): chlorophyll $a$ and POC from the MODIS Aqua satellite; lines are five-point running means. Color scheme for May 2012 (red), January 2013 (blue), and March 2013 (green). Open and filled graphics in (a) and (b) correspond to the week previous to and during each expedition. Panel (b): from left to right successive bar pairs depict satellite chlorophyll and satellite POC; crosshatched bars denote 0-20 m transmissometer POC. Panel (c): POC $_{\text {ATN }}$ flux for January (blue circles), March (green squares), and May (red triangles); the large filled symbols are a grand average for a particular depth, and small open symbols denote $1.6 \mathrm{~h}$ averaged data. Solid and dashed blue lines are Martin curve fits to January 20013 data corresponding to $b$ values of 0.858 and 0.36 , respectively. Panel (d): PIC $_{\mathrm{POL}}$ flux profiles; symbols as in (c).
Fig. A2) were $4.1 \pm 0.7$ (January), $17.5 \pm 3.4$ (March), and $15.4 \pm 5.7 \mu \mathrm{M}$ (May). POC was most variable in May 2012, with concentrations rising from $\sim 10$ to $25 \mu \mathrm{M}$ over the period of observations reflecting the progression of a plankton bloom southward from Point Conception. Corresponding euphotic zone depths (EZDs) based on the 1 einstein $\mathrm{m}^{-2} \mathrm{~d}^{-1}$ isolume (EZD for $1 \%$ light level in parentheses) were 50 (68), 20 (23), and 25 (26) $\mathrm{m}$, respectively (Sect. 2.4). January and March 2013 showed little temporal POC trend, indicating a quasi steady-state balance of photosynthesis and loss processes (Appendix Sect. A2; Fig. A2).

Figure 6 shows MODIS Aqua chlorophyll and POC time series, averaged MODIS chlorophyll and POC values for each cruise period and the previous week, averaged upper $20 \mathrm{~m}$ POC from CTD casts, and depth profiles of POC $\mathrm{ATN}_{\mathrm{ATN}}$ and $\mathrm{PIC}_{\mathrm{POL}}$ flux. Satellite-retrieved POC values agreed well with transmissometer estimates for March and May and were lowest in January 2013, although the January values were approximately 2.5 times higher than transmissometer estimates. Imagery of the area in January the week prior to our cruise showed a patchy (rather than organized) structure in chlorophyll distribution. During the time of the expedition, distributions were nearly spatially invariant on the scale of the study area (Supplement, Appendix Sect. A3, Fig. A3). From all perspectives, January 2013 had the lowest phytoplankton biomass but by far the highest fluxes of POC and PIC.

\subsection{Particle flux profiles}

Averaged $\mathrm{POC}_{\mathrm{ATN}}$ and $\mathrm{PIC}_{\mathrm{POL}}$ flux profiles provide systematic quantification of the depth trends of sedimentation. In

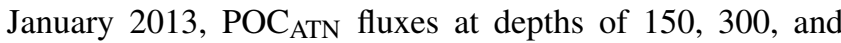
$500 \mathrm{~m}$ were 67,85 , and $35 \mathrm{mATN} \mathrm{cm}^{2} \mathrm{~cm}^{-2} \mathrm{~d}^{-1}$, respectively; in March 2013 at similar depths, flux was between 6 to $7 \mathrm{mATN} \mathrm{cm}^{2} \mathrm{~cm}^{-2} \mathrm{~d}^{-1}$; values in May 2012 for the 450 $900 \mathrm{~m}$ interval fell between 2 and $3 \mathrm{mATN} \mathrm{cm} \mathrm{cm}^{-2} \mathrm{~d}^{-1}$ with no depth trend. $\mathrm{PIC}_{\mathrm{POL}}$ flux trends roughly followed those for $\mathrm{POC}_{\mathrm{ATN}}$ flux. PIC $\mathrm{POL}$ fluxes at 150,300 , and $500 \mathrm{~m}$ depths were 96,122 , and $63 \mathrm{ppm} \mathrm{cm}^{2} \mathrm{~cm}^{-2} \mathrm{~d}^{-1}$ (January 2013) and 33, 15, and $16 \mathrm{ppm} \mathrm{cm}^{2} \mathrm{~cm}^{-2} \mathrm{~d}^{-1}$ (March 2013); the apparent decrease in PIC flux with depth from 2.8 to $0.5 \mathrm{ppm} \mathrm{cm}^{2} \mathrm{~cm}^{-2} \mathrm{~d}^{-1}$ in May 2012 may be a consequence of the low flux condition.

For both $\mathrm{POC}_{\mathrm{ATN}}$ and $\mathrm{PIC}_{\mathrm{POL}}$ flux, it is also notable that the $1.8 \mathrm{~h}$ averaged fluxes for each depth ranged over a factor of 10 relative to their average for the May and March periods but ranged by less than a factor of 2 in the high flux period of January 2013. This suggests that sedimentation is more uniform when large aggregates dominate.

The profile of $\mathrm{PIC}_{\mathrm{POL}} / \mathrm{POC}_{\mathrm{ATN}}$ ratio (Fig. 7) shows a depth-dependent increase from 1.4 to 2.4 in January, indicating preferential loss of POC with sinking. In March, $\mathrm{PIC}_{\mathrm{POL}} / \mathrm{POC}_{\mathrm{ATN}}$ ratios slightly decreased with depth from 4.6 to 3.7. In May 2012, the PIC / POC ratio decreased from 


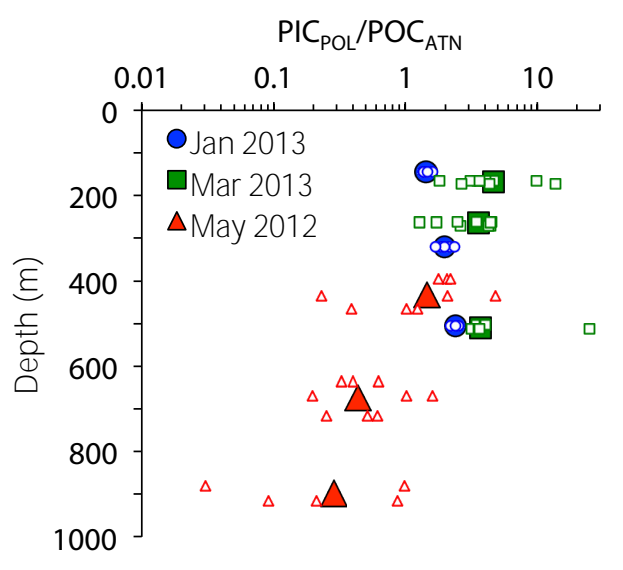

Figure 7. Depth profiles of the ratio of PIC and POC flux proxies. Results show that highest relative contribution of PIC occurred in March 2013. January and May values near $500 \mathrm{~m}$ are comparable.

1.5 to 0.3 between 430 and $900 \mathrm{~m}$. The fact that PIC / POC can decrease with depth suggests preferential carbonate dissolution can and does occur in shallow waters, a finding consistent with Bishop and Wood (2008). These observations confirm that the relative contribution of carbonates to aggregate ballasting varies with time.

\subsection{Comparison of surface-tethered optical sedimentation recorder (OSR) flux with CFE flux}

In January 2013, an OSR system, identical to the OSR on the CFE, was deployed at $237 \mathrm{~m}$ tethered below a buoy system at the surface (Appendix Sect. A4, Fig. A4). This BUOY-OSR system was engineered to collect samples needed to calibrate the $\mathrm{POC}_{\mathrm{ATN}}$ and $\mathrm{PIC}_{\mathrm{POL}}$ data; however, this approach did not succeed as intended. The $\mathrm{POC}_{\mathrm{ATN}}$ time series from CFE and BUOY-OSR are compared in Fig. 8. The BUOY-OSR yielded POC $_{\mathrm{ATN}}$ and PIC $\mathrm{CTTN}_{\mathrm{ATN}}$ fluxes of $3.6 \mathrm{mATN} \mathrm{cm}^{2} \mathrm{~cm}^{-2} \mathrm{~d}^{-1}$ and $2.2 \mathrm{ppm} \mathrm{cm}^{2} \mathrm{~cm}^{-2} \mathrm{~d}^{-1}$, respectively, approximately 25 -fold and 50-fold lower than CFE fluxes at 144 and $320 \mathrm{~m}$ depths. At the same time, BUOY-OSR and CFE images showed that the two systems collected aggregates of a completely different morphology and size distribution (Fig. 9). The CFE images showed abundant $5 \mathrm{~mm}$ to centimeter-sized aggregates. The BUOY-OSR collected only fragments of these aggregates and few particles larger than $2 \mathrm{~mm}$.

Figure 10 shows cumulative volume attenuance size distributions corresponding to samples collected in January 2013 by the CFE and BUOY-OSR. We selected CFE images for depths of $144 \mathrm{~m}(*$ in Fig. 8a), 320, and $507 \mathrm{~m}$. We also selected the BUOY-OSR image (* in Fig. 8b) and another taken at the exact same time as the first CFE image. Other BUOY-OSR images were analyzed for the rest of the time series. CFE images were either the first or second image after stage cleaning since subsequent images had multiple cases of particle overlap. The BUOY-OSR images analyzed were from just before stage cleaning since no particles were overlapping. Size distribution analysis was performed using ImageJ software, with an attenuance threshold $>0.02$ and a size threshold of at least two pixels for a particle. Particles were classified according to their equivalent circular diameter (ECD), with the lower size limit of $20 \mu \mathrm{m}$. Volume attenuance for each particle was computed (the product of particle area and attenuance). Results were summed cumulatively from largest to smallest particle size and then normalized by total volume attenuance (Table 2; Fig. 10). In January $2013,>96 \%$ of normalized cumulative volume attenuance (NCVA) was found in the $>1000 \mu \mathrm{m}$ size range in CFE data at all depths. In contrast, BUOY-OSR results typically show less than half of the cumulative volume attenuance in aggregates larger than $1000 \mu \mathrm{m}$; this is consistent with the particles being fragments of the larger aggregates and consistent with the factor of 20 difference in observed attenuance flux. If we were to eliminate all aggregates larger than $1500 \mu \mathrm{m}$ from January CFE data, then there is close agreement with the NCVA size distributions derived from BUOY-OSR data. During the period when current flow across the BUOY-OSR fell below $2 \mathrm{~cm} \mathrm{~s}^{-1}$, analysis of the BUOY-OSR image shows that nearly $50 \%$ of the aggregate volume attenuance was in the 2000-5000 $\mu \mathrm{m}$, i.e., large, size range. In other words, the surface-tethered OSR began sampling larger aggregates.

Although BUOY-OSR and CFE were operating at different depths, and were separated by $\sim 9 \mathrm{~km}$ in our study area (Fig. 1, Table 1), there was no indication in CTD or optics profiles that there was any discontinuity or advective feature at $237 \mathrm{~m}$ that would lead to biasing the BUOY-OSR results low. Nor was there any indication in remote sensing imagery (Supplement) of nearby fronts or eddy structures. Furthermore, spatial chlorophyll variability was less than $20 \%$ in our study area (Appendix Sect. A3).

Figure 11 shows CFE NCVA-PSDs from all three expeditions compared with January BUOY-OSR data and further demonstrates that the CFE captured a greater loading of large particles than the BUOY-OSR. All lines of evidence indicate a major bias against aggregates larger than millimeter in size by the surface-tethered BUOY-OSR.

\subsection{POC flux estimates}

In the absence of calibration sample data, calculations based on particle geometry, thickness, dry-weight density, and organic-matter percentages (Sect. 2.3 based on Bishop et al., 1978) yield a scaling factor of 2.8 , which can be used to convert the optical $\mathrm{POC}_{\text {ATN }}$ flux $\left(\mathrm{mATN} \mathrm{cm}^{2} \mathrm{~cm}^{-2} \mathrm{~d}^{-1}\right)$ to POC flux (mmol m $\left.\mathrm{m}^{-2} \mathrm{~d}^{-1}\right)$. POC flux was thus estimated to be 190,240 , and $100 \mathrm{mmol} \mathrm{C} \mathrm{m}^{-2} \mathrm{~d}^{-1}$ in January 2013 (at $144,320$, and $506 \mathrm{~m}), \sim 18 \mathrm{mmol} \mathrm{C} \mathrm{m}^{-2} \mathrm{~d}^{-1}$ in March 2013 (from 170 to $508 \mathrm{~m}$ ), and $\sim 6 \mathrm{mmol} \mathrm{C} \mathrm{m}^{-2} \mathrm{~d}^{-1}$ in May 2012 (430 to $900 \mathrm{~m}$ ). We similarly estimate $\sim 10 \mathrm{mmol} \mathrm{C} \mathrm{m}^{-2} \mathrm{~d}^{-1}$ at $237 \mathrm{~m}$ during the January 2013 BUOY-OSR deployment. 

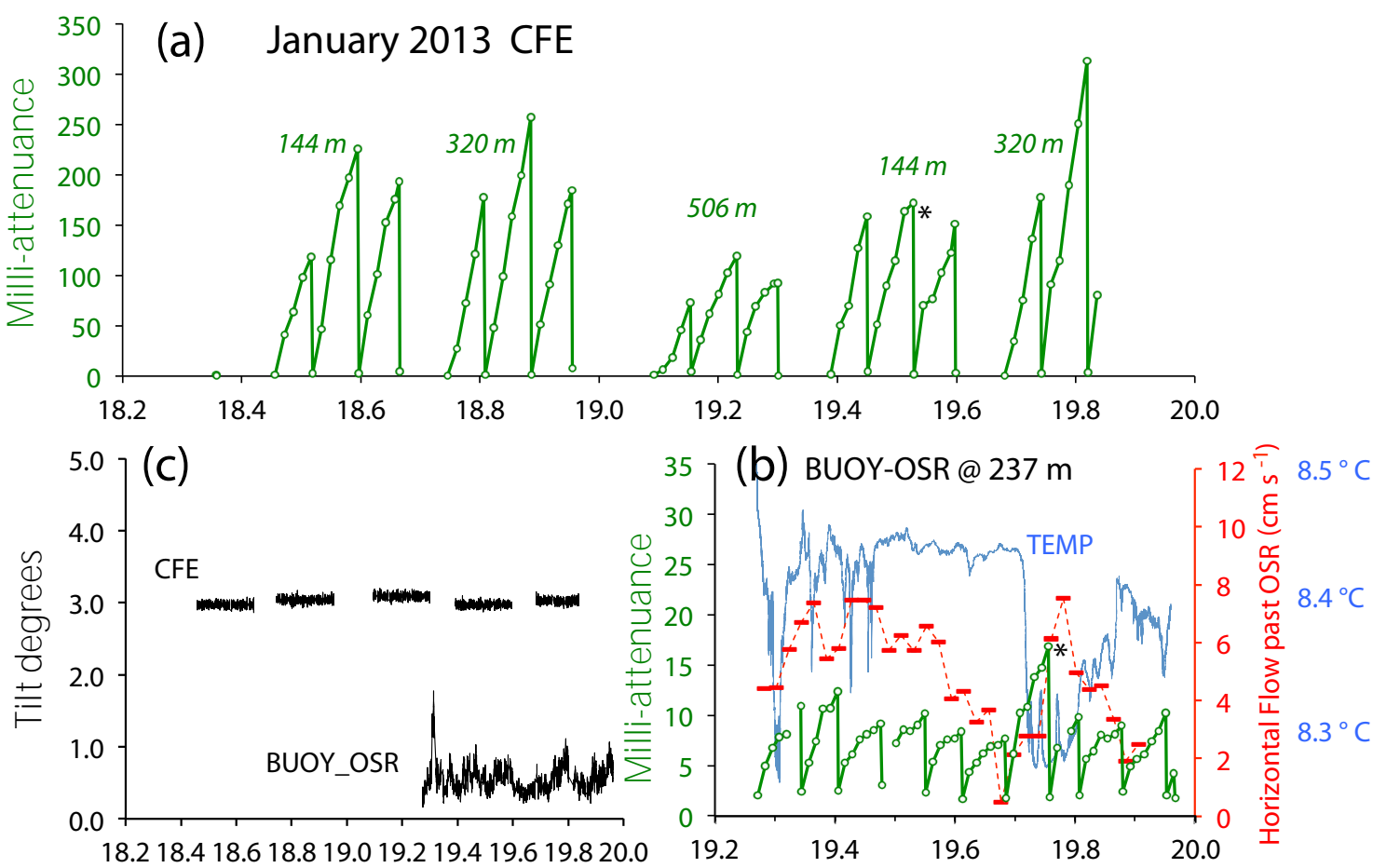

Days since Jan 12013 0:00

Figure 8. Time series of image attenuance from CFE and BUOY-OSR deployments in the Santa Cruz Basin during January 2013. Time axis shows days elapsed since 1 January at 00:00 UTC. In (a) and (b), the green lines depict the ATN time series. In (b), red symbols depict currents relative to the BUOY-OSR at a depth of $237 \mathrm{~m}$ that were calculated using ship broadband acoustic current profiler data (RDI Instruments, Ocean Surveyor 75) using methods of Hummon and Firing (2003) and 30 min BUOY-OSR GPS positions. The current dropped briefly below $1 \mathrm{~cm} \mathrm{~s}^{-1}$ and the rate of accumulation of particles in the BUOY-OSR increased. This moment was also the time when the first large aggregates were seen. Also shown in (b) in blue is the temperature time series from the logging CTD. The most obvious effect on particle collection rate by the BUOY-OSR was the relative lull in currents near day 19.68. Images from samples indicated by an asterisk are compared in Fig. 9. Panel (c): time series of CFE and BUOY-OSR tilt in degrees. CFE tilt averaged $3^{\circ}$, whereas BUOY-OSR tilt averaged $0.5^{\circ}$.
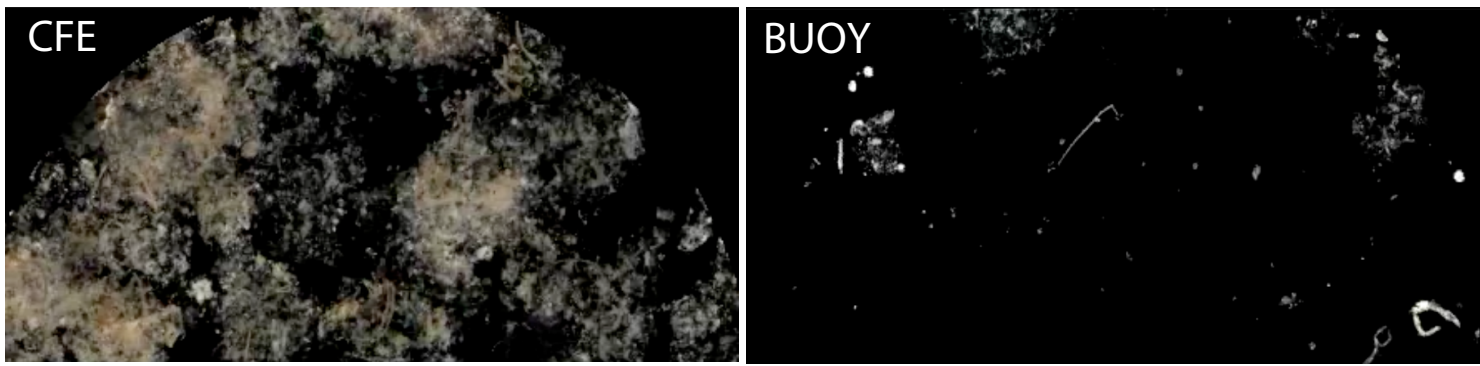

Figure 9. Comparison of representative dark field images of accumulated settling particles over a $1.8 \mathrm{~h}$ period from an optical sedimentation recorder (OSR) on the Carbon Flux Explorer (CFE, left) vs. that from a surface BUOY-tethered OSR (right) during NH1301 (January 2013). The CFE was observing sedimentation at $320 \mathrm{~m}$ (image 21:14 UTC). The BUOY-OSR was deployed at 237 m (image 18:07 UTC). Each image is $2.5 \mathrm{~cm}$ across and pixel resolution is $13 \mu \mathrm{m}$. The large fluffy $0.5-1.0 \mathrm{~cm}$ sized marine-snow aggregates were almost completely missed by the BUOY OSR. Winds were near calm $\left(<5 \mathrm{~m} \mathrm{~s}^{-1}\right)$ and surface waves and swell were almost entirely absent. The BUOY system had $\sim 0.5^{\circ}$ of tilt. The only difference between the CFE and BUOY was the absence and presence of tidally fluctuating horizontal currents of up to $8 \mathrm{~cm} \mathrm{~s}^{-1}$. Only fragments of the aggregate particles were seen in the BUOY samples. 
Table 2. Volume attenuance size distributions for CFE and BUOY-OSR samples from January 2013.

\begin{tabular}{|c|c|c|c|c|c|c|c|c|c|c|c|}
\hline $\begin{array}{l}\text { Diameter }{ }^{1} \\
(\mu \mathrm{m})\end{array}$ & \multicolumn{2}{|c|}{$\begin{array}{c}144 \mathrm{~m} \mathrm{CFE} \\
2013012011: 11\end{array}$} & \multicolumn{2}{|c|}{$\begin{array}{c}320 \mathrm{~m} \mathrm{CFE} \\
2013012016: 42\end{array}$} & \multicolumn{2}{|c|}{$\begin{array}{c}507 \mathrm{~m} \mathrm{CFE} \\
2013012005: 56\end{array}$} & \multicolumn{3}{|c|}{$\begin{array}{c}237 \text { m BUOY } \\
20130120 \text { AVG. }\end{array}$} & \multicolumn{2}{|c|}{$\begin{array}{c}237 \mathrm{~m} \mathrm{BUOY}^{3} \\
2013012018: 08\end{array}$} \\
\hline$>5000$ & $0.462^{4}$ & $0.462^{5}$ & 0.000 & 0.000 & 0.776 & 0.776 & 0.000 & 0.000 & \pm 0.000 & 0.000 & 0.000 \\
\hline $2000-5000$ & 0.441 & 0.903 & 0.978 & 0.978 & 0.150 & 0.926 & 0.065 & 0.065 & \pm 0.130 & 0.494 & 0.494 \\
\hline 1000-2000 & 0.059 & 0.962 & 0.000 & 0.978 & 0.055 & 0.981 & 0.353 & 0.418 & \pm 0.090 & 0.169 & 0.662 \\
\hline 500-1000 & 0.014 & 0.976 & 0.007 & 0.984 & 0.003 & 0.983 & 0.250 & 0.668 & \pm 0.070 & 0.153 & 0.815 \\
\hline $200-500$ & 0.015 & 0.992 & 0.005 & 0.989 & 0.011 & 0.994 & 0.245 & 0.913 & \pm 0.022 & 0.144 & 0.959 \\
\hline $100-200$ & 0.005 & 0.996 & 0.007 & 0.996 & 0.003 & 0.997 & 0.064 & 0.977 & \pm 0.006 & 0.030 & 0.989 \\
\hline $50-100$ & 0.003 & 0.999 & 0.003 & 0.999 & 0.002 & 0.999 & 0.017 & 0.994 & \pm 0.001 & 0.008 & 0.997 \\
\hline $20-50$ & 0.001 & 1.000 & 0.001 & 1.000 & 0.001 & 1.000 & 0.006 & 1.000 & \pm 0.000 & 0.003 & 1.000 \\
\hline
\end{tabular}

${ }^{1}$ Diameter is equivalent circular diameter of particle with the same area. ${ }^{2}$ Averages (excluding 18:08 data) for BUOY data; third column ( \pm ) is SD of cumulative data. ${ }^{3}$ Currents below $3 \mathrm{~cm} \mathrm{~s}^{-1}$ for $60 \mathrm{~min} .{ }^{4}$ Fraction of total volume attenuance for indicated size interval. ${ }^{5}$ Normalized cumulative volume attenuance for particles greater than lower limit of size interval.

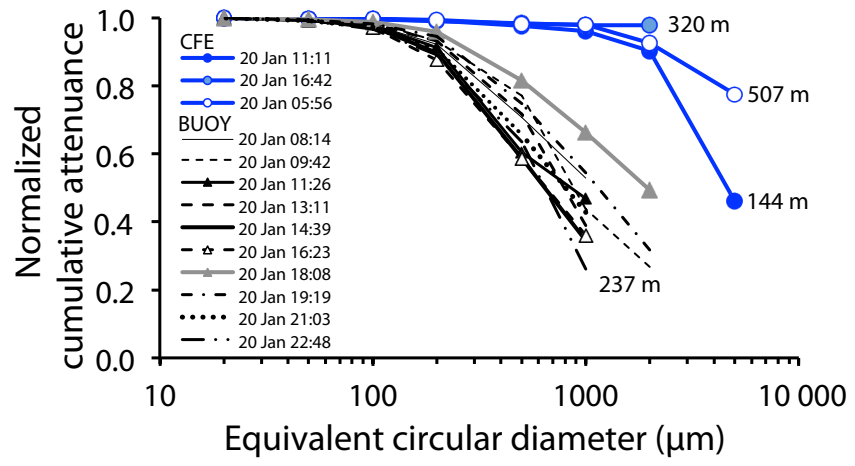

Figure 10. Comparison of normalized cumulative volume attenuance size particle distribution (NCVA-PSD) for images from CFE and BUOY-OSR systems, January 2013. Over $96 \%$ of the cumulative volume attenuance loading was in the $>1000 \mu \mathrm{m}$ fraction in CFE samples. The BUOY system images at 11:26 and 18:08 corresponded to times when current velocity above the mouth of the trap was $6 \mathrm{~cm} \mathrm{~s}^{-1}$ and less than $2 \mathrm{~cm} \mathrm{~s}^{-1}$, respectively. The NCVAPSD for the BUOY-OSR can be matched by eliminating all of the $>1500 \mu \mathrm{m}$ sized material from the CFE size distributions.

\section{Discussion}

\subsection{Surface biomass and export in coastal waters}

The high January 2013 POC flux values of 190 and $240 \mathrm{mmol} \mathrm{C} \mathrm{m}^{-2} \mathrm{~d}^{-1}$ to depths of 144 and $320 \mathrm{~m}$ are remarkable from several perspectives. Firstly, cases where the imaging stage was almost completely covered with material in $1.8 \mathrm{~h}$ had been never before encountered in our previous deployments of CFEs for missions totalling over 100 days (mostly in summer time conditions). Secondly, these high particle accumulation rates were observed in the wintertime at a time when both remotely sensed and in-water optical measures of particle stocks were low. Thirdly, the magnitude of the January 2013 POC flux, estimated from CFE data, was approximately 8 times higher than the high-

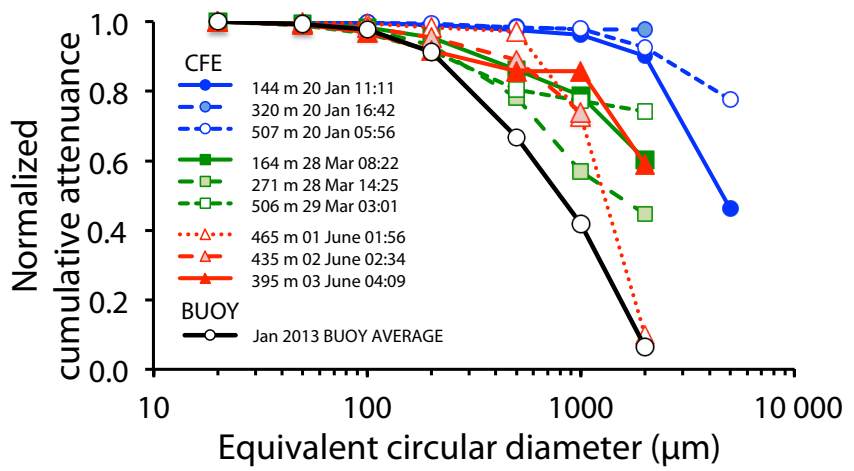

Figure 11. Comparison of normalized cumulative volume attenuance particle size distributions (NCVA-PSD) from CFE deployments in May 2012 (red lines and symbols), January 2013 (blue), and March 2013 (green). Shown in black is the average NCVA-PSD from BUOY-OSR deployments. No CFE data from any of the three expeditions overlapped BUOY-OSR results from January 2013; in all cases, larger particles were observed by the CFE.

est sedimentation rates measured using surface-tethered (at 100 and $200 \mathrm{~m}$ ) and moored sediment traps (near $500 \mathrm{~m}$ ) in the nearby Santa Barbara (Thunnel, 1998; August 1993 to September 1996) and San Pedro basins (Collins et al., 2011; January 2004 through December 2007). In both these studies, POC fluxes in moored trap samples collected over 4 years at a depth of $500 \mathrm{~m}$ were typically $3 \mathrm{mmol} \mathrm{C} \mathrm{m}^{-2} \mathrm{~d}^{-1}$, with rare values as high as $15 \mathrm{mmol} \mathrm{m}^{-2} \mathrm{~d}^{-1}$. The much sparser surface-tethered trap observations (Collins et al., 2011) were no higher than $28 \mathrm{mmol} \mathrm{C} \mathrm{m}^{-2} \mathrm{~d}^{-1}$. The finding of a high sedimentation rate during wintertime low-biomass conditions in California coastal waters has not been reported in the multiyear moored sediment trap observations.

The May 2012 fluxes of $6 \mathrm{mmol} \mathrm{m}^{-2} \mathrm{~d}^{-1}$ observed by CFE were the lowest of the study, at a time when surface waters had high particle concentrations, thus implying high recycling and shallow remineralization. The finding of low export beneath plankton blooms in coastal waters reinforces 
Table 3. Martin curve fit parameters.

\begin{tabular}{lrrrrrrr}
\hline Time & $\begin{array}{r}Z_{\text {ref }} \\
(\mathrm{m})\end{array}$ & $\Phi_{Z_{\text {ref }}}^{1}$ & $b$ & $\mathrm{SD}^{1}$ & $\Phi_{Z_{\text {ref }}}$ & $b$ & $\mathrm{SD}$ \\
\hline Jan 2013 & 50 & 252.0 & 0.858 & 34.7 & 115.0 & 0.36 & 23.3 \\
Mar 2013 & 20 & 57.5 & 0.858 & 2.3 & 11.4 & 0.22 & 0.4 \\
May 2012 & 25 & 35.0 & 0.858 & 1.0 & 3.8 & 0.17 & 0.6 \\
\hline${ }^{1}$ Units are in mATN cm ${ }^{2} \mathrm{~cm}^{-2}$. & & & & &
\end{tabular}

the findings in the open ocean that high surface biomass does not imply high export to depth (Bishop and Wood, 2009; Lam and Bishop 2007; Ebersbach et al., 2011).

The low surface biomass observed in January 2013 could indicate either a state of nutrient limitation of photosynthesis or a state of efficient transfer of primary produced organic matter to grazers and efficient particle export through the upper $500 \mathrm{~m}$. We rule out nutrient limitation in our case, as mixed layers consistently shallower than $10 \mathrm{~m}$ and surface temperatures of $12.5^{\circ} \mathrm{C}$ indicated that upwelling conditions were prevalent. Furthermore, we observed intense activity of marine mammals and sea birds feeding on abundant macroinvertebrates and fish during this period - which suggests that consumers were the source of the sinking aggregated material in the water column at this time. Many of the large aggregates seen in both January and March 2013 closely resemble abandoned appendicularian houses described by Alldredge and Silver (1988). Animations of CFE imagery are provided in the Supplement for further exploration.

Physically driven aggregative processes were not likely in January and March 2013, as winds were below $5 \mathrm{~m} \mathrm{~s}^{-1}$ and averaged $2.5 \mathrm{~m} \mathrm{~s}^{-1}$. In May 2012, winds were below $10 \mathrm{~m} \mathrm{~s}^{-1}$ and averaged $3 \mathrm{~m} \mathrm{~s}^{-1}$. Surface waves and swell were almost completely absent in January and March. Acoustic Doppler current profiler (ADCP) records showed that currents were dominated by tidal fluctuations and not by eddy structures. The low biomass condition observed in January is therefore most consistent with biologically mediated export.

We note that the 5-day running mean of satellite chlorophyll and POC levels appears to be nearly halved in a week (Fig. 6a, b), just before the study period in January. The decrease suggests that active grazing and export were in progress. Satellite imagery from January 2013 (Supplement) shows a patchy POC and chlorophyll distribution without obvious eddy structures or fronts nearby.

Our observations show that $\mathrm{POC}_{\mathrm{ATN}}$ flux profiles (Fig. 6) attenuate with depth, albeit not following the classic Martin et al. (1987) curve fit $\left(\Phi z=\Phi_{Z_{\text {ref }}} /\left(Z / Z_{\text {ref }}\right)^{b}, Z\right.$ is depth, $Z_{\text {ref }}=100 \mathrm{~m}, \Phi$ is flux, and $b=0.858$ ). Using light-based euphotic depths of 50, 20, and $25 \mathrm{~m}$ for January, March, and May as the $Z_{\text {ref }}$ values for particle remineralization (Buesseler and Boyd, 2009), we derive Martin's " $b$ " factors of $0.36,0.22$, and 0.17 , respectively, far lower than the accepted $b$ value (Table 3). There are multiple limitations to this exer- cise; these include likely temporal variation of flux at a particular depth with time of day (see, e.g., Fig. 15 in Bishop et al., 1987), depths sampled being $100 \mathrm{~m}$ deeper than the base of the euphotic zone, and the limited time of the study. That said, it is clear that in January 2013, the export may have been high enough to overwhelm the capacity of detritus feeders to reduce the flux. In May and March, all evidence is consistent with high recycling of the sinking POC in waters shallower than our 400 and $125 \mathrm{~m}$ observation points, respectively.

The fact that the PIC / POC ratio can decrease with depth suggests that carbonate dissolution may occur in shallow waters of the Pacific, a finding consistent with Bishop and Wood (2008). Also, we note that living foraminifera and empty foraminifera shells were predominantly associated with large aggregates in January. While the occurrence of empty shells in aggregates would not be exceptional, the finding of living foraminifera suggests an active association with these particles.

\subsection{Surface-tethered BUOY-OSR vs. Lagrangian CFE fluxes}

Our comparison of fluxes recorded by the CFE and a surfacetethered BUOY-OSR in January 2013 found a factor of 20 difference in collection rate (Figs. 8 and 9), consistent with the loss of all aggregates $>1500 \mu \mathrm{m}$ in size. CFE collection rates, ignoring the $>1500 \mu \mathrm{m}$ fraction in March 2013 and May 2012, would be approximately 4 times lower and 3 times lower, respectively (Fig. 11). This was surprising in light of reports that there are less than "factor of 2" differences in sedimentation measured using surface-tethered particle interceptor traps (Martin et al., 1987; PITS) and neutrally buoyant sediment traps (NBST) deployed in oligotrophic waters near Bermuda (Buesseler et al., 2000; Stanley et al., 2004; Owens et al., 2013). In our study, the particles mostly absent from the BUOY-OSR were large aggregates in the millimeter to centimeter size class (Figs. 9, 10,11). The only time when large aggregates appeared in the BUOY-OSR imagery was during periods when the flow of water across the mouth of the BUOY-OSR was below $2 \mathrm{~cm} \mathrm{~s}^{-1}$ (Fig. 8). Given that marine-snow aggregates typically settle at rates of $0.1-0.2 \mathrm{~cm} \mathrm{~s}^{-1}$ (Alldredge and Silver, 1988), the trajectory of the aggregates across the BUOY-OSR funnel would be almost horizontal, even in currents as weak as $2 \mathrm{~cm} \mathrm{~s}^{-1}$ The large aggregates are thus likely discriminated against entering the centimeter-sized trap baffle openings, which are of the same size as the particles and we hypothesize that the aggregates simply bounce back into the flow after shedding a few fragments, rather than entering the trap.

Further support for a higher coastal sedimentation than is presently recognized is provided by Stukel et al. (2011), who worked just offshore of our study area in the California Current. They compared the new production (Eppley and Peterson, 1979) " $f$ ratio" (the fraction of primary production supported by upwelled nitrate) to the ${ }^{234} \mathrm{Th}$ disequilibrium- 
based " $e$ ratio" (the fraction of primary production exported as particles), and the two should be equivalent in a food web in equilibrium. While methods agreed $300 \mathrm{~km}$ offshore, the $f$ ratio exceeded the $e$ ratio by factors of 5-7 at locations within 50 and $100 \mathrm{~km}$ from the coast. Simply stated, there is insufficient time for the ${ }^{234} \mathrm{Th}$ (half life 24 days) deficit relative to its parent ${ }^{238} \mathrm{U}$ to reach steady state in coastal waters. Subsequent surface-tethered particle interceptor trap deployments (Stukel et al., 2013) in the same area showed consistently low exports in this region where $f$ ratios are typically high (Eppley and Peterson, 1979). Our location is closer to shore. Even taking into account factors such as food web and lateral transport processes, multiple lines of evidence strongly indicate that large $>1 \mathrm{~mm}$ sized aggregates are severely undersampled by surface-tethered baffled traps.

It is important to note that sediment traps have been the sole method to date for the assessment of carbon export in coastal waters. The single profile ${ }^{234} \mathrm{Th} /{ }^{238} \mathrm{U}$ method is not applicable in the coastal environment since it relies on an assumption of a steady-state deficit and requires a timescale of multiple half-lives ( $24.1 \mathrm{~d}$ ) to reach this condition. Although the ${ }^{234} \mathrm{Th} /{ }^{238} \mathrm{U}$ method may be used to infer export from time series sampling of a water parcel, such a study has not been undertaken in nearshore California waters to our knowledge. Also, $e$-ratio estimates are calibrated with large particles sampled either using traps or pumps and the assumption is that the $\mathrm{Th}: \mathrm{C}$ ratio of all large particle phases is the same. Both methods have been shown to have large biases; in situ pumps are discussed by Bishop et al. (2012), and results presented here show undersampling of large aggregates by surface-tethered baffled traps. As there is scant literature on the size dependence of $\mathrm{Th}-\mathrm{C}$ in different large particle size classes in the coastal environment, it is thus impossible to know the accuracy of $e$-ratio export estimates.

Coordinated at-sea studies are required to intercompare the various methods of measurement of carbon export.

\section{Conclusions}

The new continuous observations of particulate flux off the coast of southern California by autonomous CFEs show high fluxes in winter when surface chlorophyll is low. The finding is consistent with high primary productivity, efficient grazing, and high export of resulting aggregate material. The finding is also consistent with Eppley and Peterson's (1979) estimate of high new production and their inferred strength of particle export in nearshore waters and, as noted above, is higher by a factor of $\sim 8$ than the highest observations made with surface-tethered and moored sediment traps in waters close to our study site. Analysis of the images of accumulated particles suggests that surface-tethered sediment traps under-sample a major class of large aggregates contributing to carbon export from surface waters. At the time of writing, it is premature to revise the carbon export attributable to coastal waters up by a factor of 20 as we do not yet know the year-round contribution of large aggregates to sedimentation. In other seasons, our POC flux estimates are closer but still elevated by greater than a factor of 2 compared with moored traps and likely a minimum of a factor of 3 based on discussion of size frequency distribution results presented in Sect. 4.1. Missing contributions of large aggregates in sediment trap collections may explain the reported imbalance between POC flux to the seafloor and benthic respiratory demand seen at a nearby station $\mathrm{M}\left(34^{\circ} 50^{\prime} \mathrm{N}, 123^{\circ} 00^{\prime} \mathrm{W}\right.$; Smith et al., 2013). We also show that particulate fluxes estimated using remotely sensed surface biomass may be overestimated sometimes or underestimated at other times, depending on the population of grazers and the efficiency of export. The CFE can provide "ocean truth" for such estimates.

There is uncertainty in the conversion of $\mathrm{POC}_{\mathrm{ATN}}$ flux to POC flux, and we have no data on the conversion of PIC $\mathrm{POL}_{\mathrm{P}}$ to PIC flux; however, the optical metrics of POC and PIC flux are robustly defined for the CFE, and the resulting images of settled particles clearly provide evidence of the food web mechanisms governing carbon export. Better calibration can only be achieved by at-sea $24 \mathrm{~h}$ deployments of CFEs modified to collect samples; we hope to report on upcoming deployments soon.

While CFE and BUOY-OSRs were not directly compared to fluxes measured simultaneously with PIT traps and thorium methods and to large particle abundances sampled by large volume in situ filtration and other methods, such a study should be undertaken in biologically dynamic waters and augmented by a framework of contemporaneous remote sensing observations, water column biology, and physics.

To date, two CFEs have each completed missions lasting 40 days offshore of California and another 10 days in the waters in the subarctic Pacific (mission duration set by ship availability) in bad weather and sea states and without biofouling issues; our lab tests show that a CFE can perform hourly observations of carbon export in the open ocean for 8 months (2-hourly frequency for 16 months, etc.). More work to enable onboard image data analysis is required to render the CFE fully autonomous.

Near shore, horizontal currents can displace a CFE from the area of intended operation in several days' time; thus, longer time series observations are difficult without a means to reposition the CFE. As the cost of a CFE is equivalent to the cost of operating a mid-size research vessel for $\sim 2$ 3 days, the job of tending CFEs for seasonal or year-round studies in the coastal environment would need to be done using autonomous surface or underwater vehicles.

In summary, we show that autonomous sampling technologies may be deployed to address many questions about the workings of the biological pump both offshore and onshore, including whether or not its strength has changed over the past several decades and whether or not it will change in the future in the face of anthropogenic $\mathrm{CO}_{2}$ warming and acidification and the exploitation of living resources of the ocean. 


\section{Data availability}

Data for plots, representative images used in this paper, and animations of image time series (at 1/4 resolution) are available as Supplement and are available from the author on request. Shipboard data sets, including meteorological, surface hydrography, and CTD cast data, were contributed to the Rolling Deck to Repository (R2R) program (http://www. rvdata.us) archives or, in the case of ADCP data, are available through the University of Hawaii. 


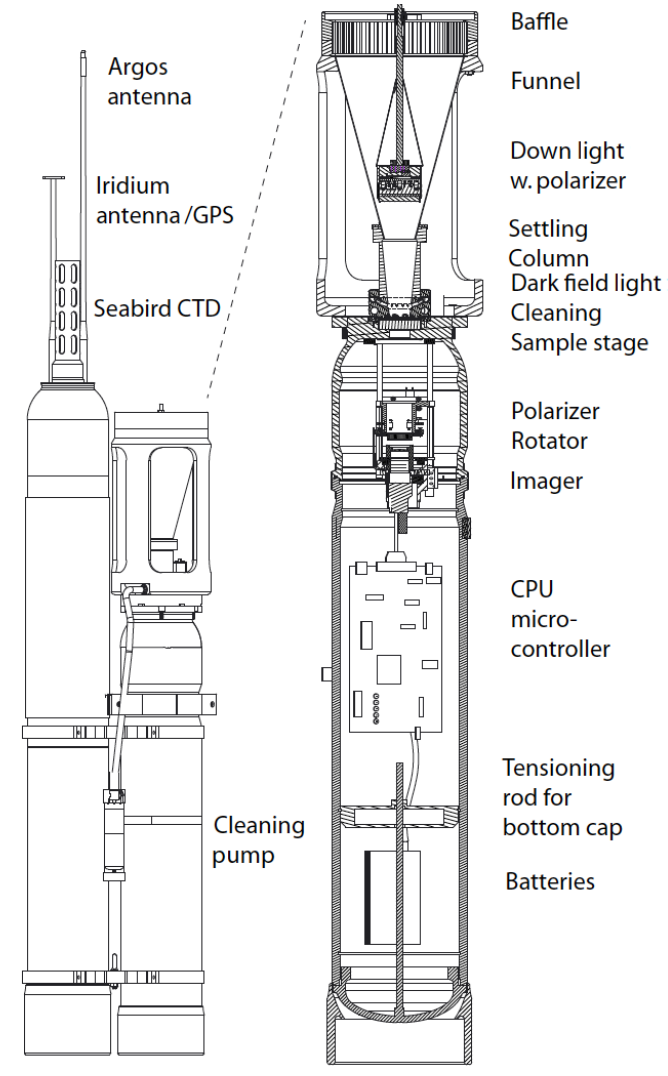

Figure A1. Drawing depicting the configuration of CFE001 and detail of lighting and imaging elements of the OSR. During operation, the OSR uses a three-axis accelerometer to monitor system tilt.

\section{Appendix A: Method details}

\section{A1 Optical sedimentation recorder on CFE}

The optical sedimentation recorder (OSR; Fig. A1) is independently powered from the SOLO float to which it is attached, and the two communicate via a hardwired link. It thus does not impact the number of profiles that the float can make beyond additional telemetry needs.

The SOLO dives to its target depth and signals to the OSR to begin operation. During time at depth, particles settle into a baffled $(5 \mathrm{~cm}$ thick $\times 1 \mathrm{~cm}$ opening hex cell) high-aspect polished titanium funnel (height $23.6 \mathrm{~cm}$; slope $75^{\circ} ; 15.4 \mathrm{~cm}$ diameter opening) and settling column (height $\sim 11 \mathrm{~cm}$ ) before depositing on a $2.5 \mathrm{~cm}$ diameter glass sample stage. The baffle is typical for the dimensions used in surface-tethered particle interceptor traps (e.g., Martin et al., 1987; Collins et al., 2011; Stukel et al., 2013).

A downward focused $5 \mathrm{~cm}$ diameter white (color temperature $2700 \mathrm{~K}$ ) light-emitting diode (LED) source with bonded linear polarizer (Meadowlark Optics, Frederick, CO) is axially aligned with the funnel and provides transmitted light (or backlit) illumination of the sample.
An annular array of 12 white LEDs provides dark field illumination. This light source is integrated within the body of a 3-D printed form designed to provide both a hydrodynamic cleaning function and to secure a $27 \mathrm{~mm}$ diameter dashed cross-hair reticle (Edmond Optics Inc., Barrington, NJ) to the pressure case window. A Seabird Inc. (Bellevue, WA) pump outfitted with an isolation valve is used to flush the sample stage during cleaning.

A substage polarizer rotator is rotated either parallel or perpendicular to the axis of the downlight polarizer. In the case of CFE001, this polarizer rotator was housed within the instrument pressure case.

Under computer control, particles are imaged with a $5 \mathrm{M}$ pixel Sumix (SMX-11M5C; Oceanside, CA) color imager in transmitted, transmitted-cross polarized, and dark field lighting modes, which are designated as TRA, POL, and DRK, respectively. Gain settings for each of the red, green, and blue (RGB) channels were adjusted so that images of the downlight yield similar count value histogram averages (to within several percentage points). The same gain settings were used for cross-polarized transmitted light illumination. For dark field, RGB channel balance was achieved by imaging salt crystals dispersed across the sample stage. The camera lens was set to F16. Shutter timing was set for each of the three modes to prevent image saturation.

\section{A2 Surface conditions, hydrography, and transmissometer data}

Sea and wind conditions during the three study periods were benign. For example, in January and March 2013, winds monitored by the ship were less than 5 and averaged $2.5 \mathrm{~m} \mathrm{~s}^{-1}$. In May 2012, winds were less than 10 and averaged $3 \mathrm{~m} \mathrm{~s}^{-1}$. Surface waves and swell were almost completely absent in January and March. In January 2013, the weather was completely cloud free which contributed to excellent satellite imagery of the area.

During all expeditions, a CTD-rosette system with a CStar (WETLabs, Inc. Philomath, OR) transmissometer and Seapoint Inc. scattering sensor was repeatedly deployed to full water column depth. Approximately 20 casts were completed during each cruise. Only transmissometer data are reported here. The transmissometer cleaning, calibration, and data processing to particle beam attenuation coefficient $\left(c_{\mathrm{p}}\right)$ follow protocols we have published (Bishop and Wood, 2008; Bishop et al., 2012). POC was calculated by multiplying the particle beam attenuation coefficient by 27 (Bishop and Wood, 2008).

Figure $\mathrm{A} 2 \mathrm{a}-\mathrm{c}$ shows $c_{\mathrm{p}}$ profiles for the three expeditions. Also shown is $0-20 \mathrm{~m}$ averaged POC from these casts. The time line for plot (d) is relative to the start of deployment of the CFE. Average and standard deviation values of $0-20 \mathrm{~m}$ averaged POC are quoted in the text.

The effects of internal waves with periods of $20-30 \mathrm{~min}$ were usually seen in CTD cast data. In March 2013, inter- 

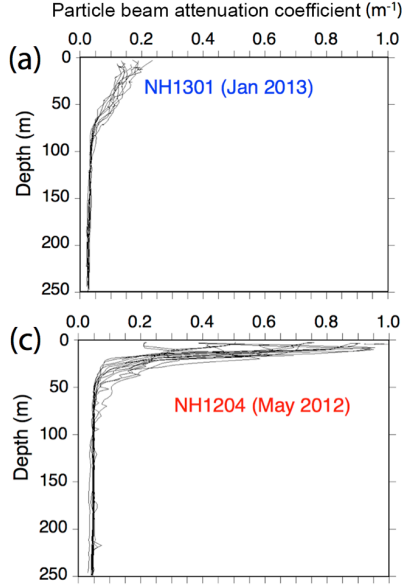
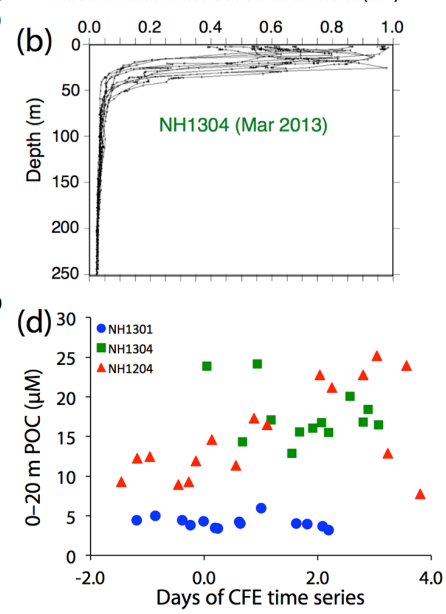

Figure A2. Panels (a-c): particle beam attenuation coefficient $\left(c_{\mathrm{p}}\right)$ profiles corresponding to NH1301 (January 2013), NH1304 (March 2013), and NH1204 (May/June 2012) expeditions. Panel (d): POC calculated for the $0-20 \mathrm{~m}$ depth interval using $c_{\mathrm{p}}$ multiplied by 27 . The $x$ axis shows days relative to the start of each CFE deployment.

nal wave amplitudes of approximately $40 \mathrm{~m}$ were observed during CTD profiles to $35 \mathrm{~m}$, repeated every $10 \mathrm{~min}$ without recovery. . During other expeditions, wave amplitudes were less than $20 \mathrm{~m}$.

\section{A3 Spatial gradients of surface chlorophyll in the study area}

To examine the detailed spatial gradients of chlorophyll in our study area, we chose locations at $33.73^{\circ} \mathrm{N}, 119.50^{\circ} \mathrm{W}$ and $33.69^{\circ} \mathrm{N}, 119.58^{\circ} \mathrm{W}$ and retrieved chlorophyll data at $1 \mathrm{~km}$ spatial resolution within a $2 \mathrm{~km}$ search radius of the two locations. These positions were $9 \mathrm{~km}$ apart. To achieve greater temporal and spatial coverage than possible with the single MODIS-Aqua product, we analyzed merged data from MODIS on the Aqua and Terra satellites and from the Visible Infrared Imaging Radiometer Suite (VIIRS) on the National Polar-orbiting Partnership Suomi satellite (Kahru et al., 2012; http://spg.ucsd.edu/Satellite_Data/California_ Current/). Images at $1 \mathrm{~km}$ resolution are provided in the Supplement.

Figure A3 shows time series of daily mean and standard deviation of chlorophyll plotted for both locations over 30day periods encompassing the days that the ship was on station in the Santa Cruz Basin and during CFE deployments. Also plotted is the relative difference in chlorophyll between the two locations. The two locations were almost always $<20 \%$ different from one another. From this we conclude that a separation of $9 \mathrm{~km}$ is not a significant cause of differences in CFE vs. BUOY-OSR results. In other words, spatial gradients of biomass in our study area were small.

\section{A4 BUOY-OSR configuration, January 2013}

Figure A4 depicts the deployment configuration of the sample-collecting BUOY-OSR used in this study. An SBE 19-plus logging CTD (Sea Bird Electronics, Bellevue, WA) recorded pressure, temperature, and salinity at $5 \mathrm{~s}$ intervals. One OSR (Buoy instrument 84) was configured identically to CFE001. The funnel assembly of the second OSR (Buoy instrument 88) had a sample stage leak enabling strong water circulation through the funnel leading to particle loss as the system was pumped up and down due to wave action. Buoy instrument 84 is considered reliable as particles remained in place where they fell as they accumulated. 

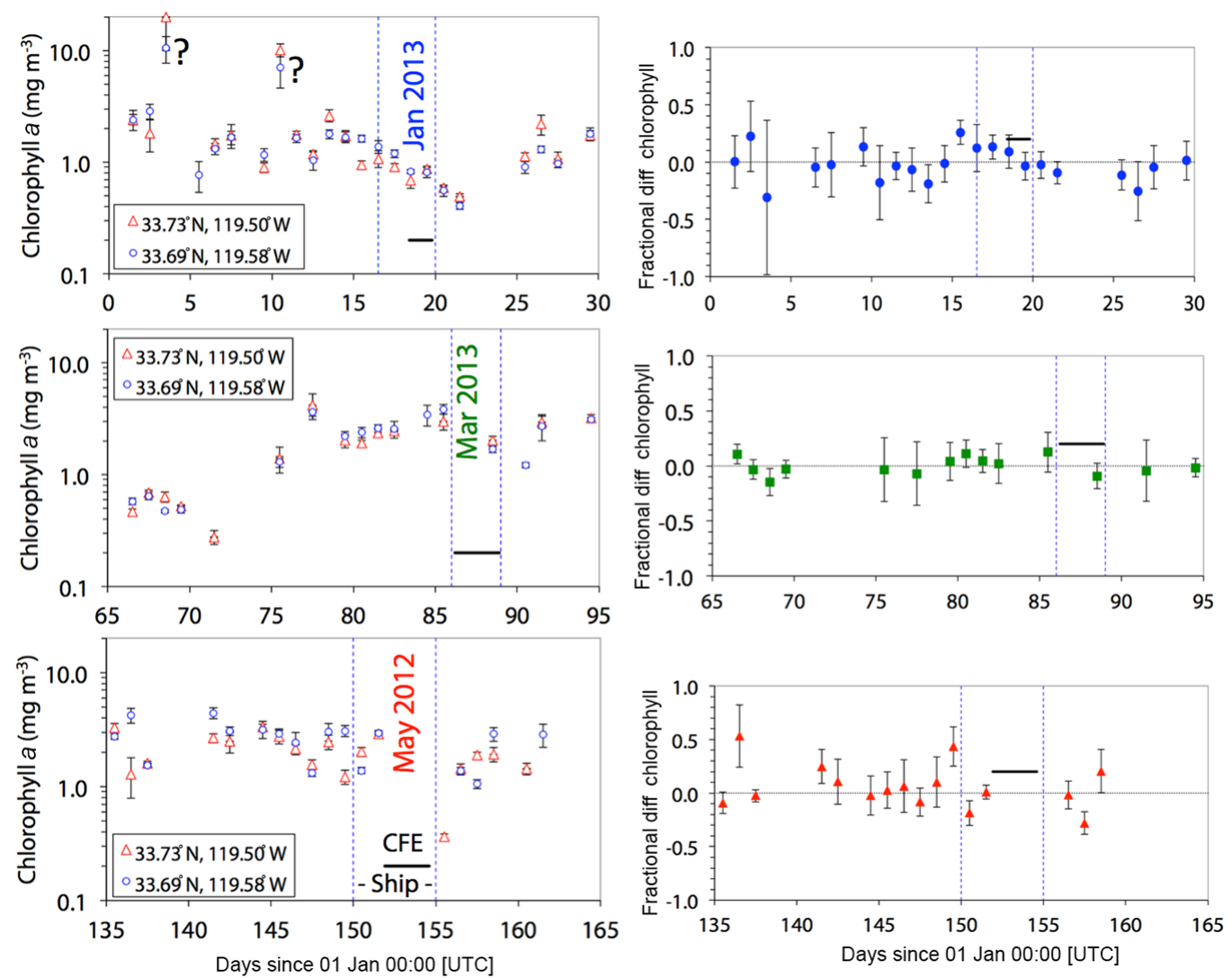

Figure A3. Left panels: means and standard deviations of chlorophyll $a$ retrieved from $1 \mathrm{~km}$ spatially resolved merged MODIS Aqua and Terra and VIIRS Sumoi products within $2 \mathrm{~km}$ radius of $33.73^{\circ} \mathrm{N}, 119.50^{\circ} \mathrm{W}$ (red triangles) and $33.69^{\circ} \mathrm{N}, 119.58^{\circ} \mathrm{W}$ (blue circles). Top to bottom: graphs correspond to times of sampling. The $1 \mathrm{~km}$ results are raw merged products. The data indicated by "?" are incongruent with the rest of the time series. Dashed blue lines denote the periods that the ship was on station in the Santa Cruz Basin study area. The black horizontal line denotes duration of CFE deployments. Right panels show the fractional difference in mean chlorophyll between the two locations. There was no systematic difference between locations. 


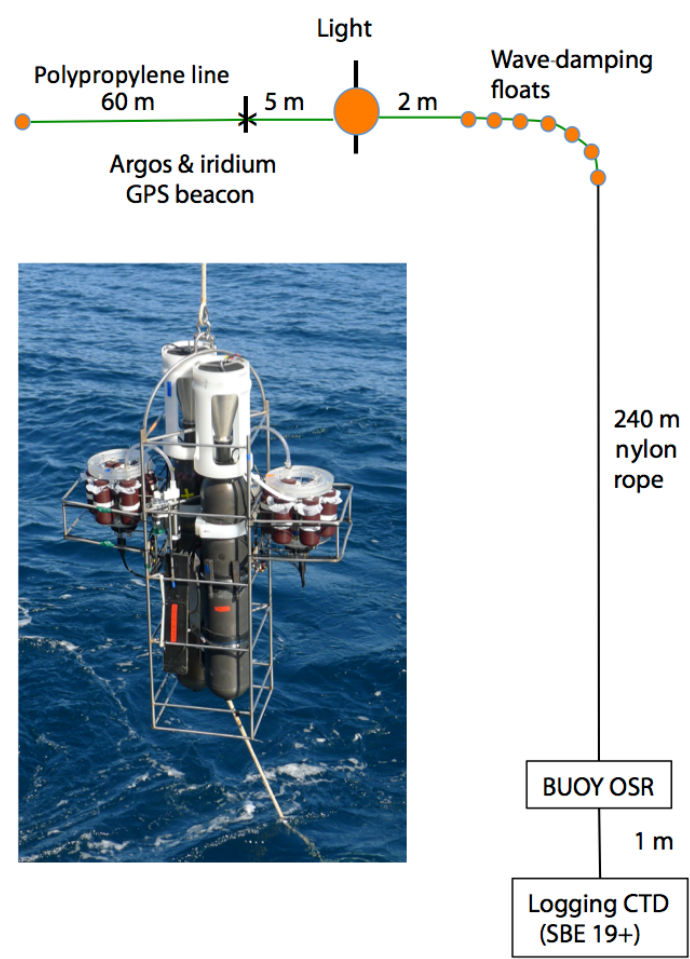

Figure A4. Photograph of the surface-tethered BUOY-OSR as deployed in January 2013. Also shown is the mooring configuration used in this study. The seven small floats spaced $1 \mathrm{~m}$ apart are intended to minimize the effects of surface wave action on the up and down motion of the subsurface sediment trap. During the January 2013 deployment, depth was $237 \mathrm{~m}$ ( $\pm 0.25 \mathrm{~m} \mathrm{SD})$; maximum peak to trough vertical motion was $1 \mathrm{~m}$. 


\section{The Supplement related to this article is available online at doi:10.5194/bg-13-3109-2016-supplement.}

Author contributions. James K. B. Bishop initiated the CFE program, was chief scientist at sea, and led the analysis and writing of this paper. Todd J. Wood played a key engineering role in all aspects of the development, deployment, programming, and operation of the CFE. Michael B. Fong analyzed MODIS Aqua and Terra and VIIRS satellite data.

Acknowledgements. The CFE was developed in close collaboration with Mike McClune and Russ Davis of the Scripps Institution of Oceanography Instrument Development Group. OSR design and construction had critical contributions from the Electrical and Mechanical engineering groups and machine shop facilities at Lawrence Berkeley National Laboratory. Alex Morales (LBNL) and 25 UC Berkeley undergraduates facilitated CFE and BUOY-OSR deployments and recoveries at sea. In particular, Gabrielle Weiss, Amelia Weiss, Andrew Bower, and Christina Hamilton contributed both at sea and in the laboratory; we also thank the resident technicians, crews, and captains of the R/V New Horizon for assistance. Jules Hummon (U Hawaii) assisted with ADCP data reprocessing. Hannah Bourne (UC Berkeley) cross-checked ADCP and BUOY-OSR current shear calculations. We thank Mati Kahru (SIO) for access to kilometer-scale chlorophyll data for our study area. We thank the three anonymous reviewers for their contributions. The CFE data sets and animated image videos are posted as a Supplement. Undergraduate participation in cruises was facilitated by the UC Berkeley Undergraduate Research Apprentice Program and by the Earth and Planetary Science Department Ramsden fund. All work reported here was sponsored by National Science Foundation grant OCE-0936143 (JKBB).

Edited by: E. Marañón

\section{References}

Alldredge, A. L.: The carbon, nitrogen, and mass content of marine snow as a function of aggregate size, Deep-Sea Res. Pt. I, 45, 52-541, 1998.

Alldredge, A. L. and Silver, M. W.: Characteristics, dynamics and significance of marine snow, Prog. Oceanogr., 20, 41-82, 1988.

Armstrong, R. A., Lee, C., Hedges, J. I., Honjo, S., and Wakeham, S. G.: A new mechanistic model for organic carbon fluxes in the ocean based on quantitative association of POC with ballast minerals, Deep-Sea Res. Pt. II., 49, 219-236, 2002.

Asper, V. L.: Measuring the flux and sinking speed of Marine Snow Aggregates, Deep-Sea Res., 34, 1-17, 1987.

Banse, C.: Reflections About Chance in My Career, and on the TopDown Regulated World, Annu. Rev. Mar. Sci., 5, 1-19, 2013.

Bé, A. W. H., Bishop, J. K. B., Sverdlove, M. S., and Gardner, W. D.: Standing Stock, Vertical Distribution, and Flux of Planktonic Foraminifera in the Panama Basin, Mar. Micropaleontol., 9, 307333, 1985.
Bishop, J. K. B. and Wood, T. J.: Particulate Matter Chemistry and Dynamics in the Twilight Zone at VERTIGO ALOHA and K2 Sites, Deep-Sea Res. Pt. I, 55, 1684-1706, doi:10.1016/j.dsr.2008.07.012, 2008.

Bishop, J. K. B. and Wood, T. J.: Year Round Observations of Carbon Biomass and Flux Variability in the Southern Ocean, Global Biogeochem. Cy., 23, GB2019, doi:10.1029/2008GB003206, 2009.

Bishop, J. K. B., Ketten, D. R., and Edmond, J. M.: Chemistry, biology and vertical flux of particulate matter from the upper $400 \mathrm{~m}$ of the Cape Basin in the Southeast Atlantic Ocean, Deep-Sea Res., 25, 1121-1161, 1978.

Bishop, J. K. B., Stepien, J. C., and Wiebe, P. H.: Particulate matter distributions, chemistry and flux in the Panama Basin: response to environmental forcing, Prog. Oceanogr., 17, 1-59, 1987.

Bishop, J. K. B., Wood, T. J., Davis, R. E., and Sherman, J. T.: Robotic Observations of Enhanced Carbon Biomass and Export at $55^{\circ} \mathrm{S}$ During SOFeX, Science, 304, 417-420, 2004.

Bishop J. K. B., Lam, P. J., and Wood T. J: Getting good particles: Accurate sampling of particles by large volume in-situ filtration, Limnol. Oceanogr--Methods, 10, 681-710, 2012.

Buesseler, K. O. and Boyd, P. W.: Shedding light on processes that control particle export and flux attenuation in the twilight zone of the open ocean, Limnol. Oceanogr., 54, 1210-1232, 2009.

Buesseler, K. O., Steinberg, D. K., Michaels, A. F., Johnson, R. J., Andrews, J. E., Valdes, J. R., and Price, J. F.: A comparison of the quantity and composition of material caught in a neutrally buoyant versus surface-tethered sediment trap, Deep-Sea Res. Pt. I, 47, 277-294, 2000.

Buesseler, K. O., Antia, A. N., Chen, M., Fowler, S. W., Gardner, W. D., Gustafsson, O., Harada, K., Michaels, A. F., Rutgers van der Loeff, M., Sarin, M., Steinberg, D. K., and Trull, T.: An assessment of the use of sediment traps for estimating upper ocean particle fluxes, J. Mar. Res., 65, 345-416, 2007.

Burd, A. B., Hansell, D. A., Steinberg, D. K., Anderson, T. R., Arístegui, J., Baltar, F., Beaupre, S. R., Buesseler, K. O., Dehairs, F., Jackson, G. A., Kadko, D. C., Koppelmann, R., Lampitt, R. S., Nagata, T., Reinthaler, T., Robinson, C., Robison, B. H., Tamburini, C., and Tanaka, T.: Assessing the apparent imbalance between geochemical and biochemical indicators of meso-and bathypelagic biological activity: what the @\$\#! is wrong with present calculations of carbon budgets?, Deep-Sea Res. Pt. II, 57, 1557-1571, 2010.

Collins, L. E., Berelson, W., Hammond, D. E., Knapp, A., Schwartz, R., and Capone D.: Particle fluxes in San Pedro Basin, California: A four-year record of sedimentation and physical forcing, DeepSea Res. Pt. I, 58, 898-914, 2011.

Davis, R. E., Sherman, J. T., and Dufour, J.: Profiling ALACEs and other advances in autonomous subsurface floats, J. Atmos. Ocean. Technol., 18, 982-993, 2001.

Ebersbach, F., Trull, T. W., Davies, D. M., and Bray, S. G.: Controls on mesopelagic particle fluxes in the Sub-Antarctic and Polar Frontal Zones in the Southern Ocean south of Australia in summer - Perspectives from free-drifting sediment traps, DeepSea Res. Pt. II, 58, 2260-2276, 2011.

Eppley, R. W. and Peterson, B. J.: Particulate organic matter flux and planktonic new production in the deep ocean, Nature, 282, 677-680, doi:10.1038/282677a0, 1979. 
Estapa, M. L., Buesseler, K., Boss, E., and Gerbi, G.: Autonomous, high-resolution observations of particle flux in the oligotrophic ocean, Biogeosciences, 10, 5517-5531, doi:10.5194/bg-105517-2013, 2013.

Field, C. B., Behrenfeld, M. J., Randerson, J. T., and Falkowski, P. G.: Primary production of the biosphere: Integrating terrestrial and oceanic components, Science 281, 237-240, 1998,

Gardner, W. D.: Sediment trap sampling in surface waters, in: The Changing Ocean Carbon Cycle: A midterm synthesis of the Joint Global Ocean Flux Study, edited by: Hanson, D. H. and Field, C., Cambridge Univeristy Press, 240-284, 2000.

Guay, C. K. and Bishop, J. K. B.: A rapid birefringence method for measuring suspended $\mathrm{CaCO} 3$ concentrations in water, Deep-Sea Res. Pt. I, 49, 197-210, 2002.

Hedges, J. I., Baldock, J. A., Gelinas, Y., Lee, C., Peterson, M. L., and Wakeham, S. G.: The biochemical and elemental compositions of marine plankton: a NMR perspective, Mar. Chem., 78, 47-63, 2002.

Henson, S. A., Sanders, R., Madsen, E., Morris, P. J., Le Moigne, F., and Quartly G. D.: A reduced estimate of the strength of the ocean's biological carbon pump, Geophys. Res. Lett., 38, L04606, doi:10.1029/2011GL046735, 2011.

Hummon, J. M. and Firing, E.: A direct comparison of two RDI shipboard ADCPs: a 75-kHz Ocean Surveyor and a $150-\mathrm{kHz}$ Narrowband, J. Atmos. Ocean. Technol., 20, 872-888, 2003.

Kahru, M., Kudela R. M., Manzano-Sarabia M., and Mitchell B. G.: Trends in the surface chlorophyll of the California Current: Merging data from multiple ocean color satellites, Deep-Sea Res. Pt. II, 77-80, 89-98, 2012.

Lam, P. J. and Bishop, J. K. B.: High Biomass Low Export regimes in the Southern Ocean, Deep-Sea Res. Pt. II, 54, 601-638, doi:10.1016/j.dsr2.2007.01.013, 2007.

Lampitt, R. S., Boorman, B., Brown, L., Lucas, M., Salter, I., Sanders, R., Saw, K., Seeyave, S., Thomalla, S. J., and Turnewitsch, R.: Particle export from the euphotic zone: estimates using a novel drifting sediment trap, Th-234 and new production, Deep-Sea Res. Pt. I, 55, 1484-1502, 2008.

Lee, C., Peterson, M. L., Wakeham, S. G., Armstrong, R. A., Cochran, J. K., Miquel, J. C., Fowler, S. W., Hirschberg, D., Beck, A., and Xue, J.: Particulate organic matter and ballast fluxes measured using time-series and settling velocity sediment traps in the northwestern Mediterranean Sea, Deep-Sea Res. Pt., II, 56, 1420-1436, 2009.
Martin, J. H., Knauer, G. A., Karl, D. M., and Broenkow, W. W.: VERTEX: carbon cycling in the northeast Pacific, Deep-Sea Res., 34, 267-285, 1987.

Owens, S. A., Buesseler, K. O., Lamborg, C. H., Valdes, J., Lomas, M. W., Johnson, R. J., Steinberg, D. K., and Siegel, D. A.: A new time series of particle export from neutrally buoyant sediments traps at the Bermuda Atlantic Time-series Study site, Deep-Sea Res. Pt. I, 72, 34-47, 2013.

Siegel, D. A., Buesseler, K. O., Doney, S. C., Sailley, S. F., Behrenfeld, M. J., and Boyd, P. W.: Global assessment of ocean carbon export by combining satellite observations and food-web models, Global Biogeochem. Cy., 28, 16 pp., doi:10.1002/2013GB004743, 2014.

Smith, K. L., Ruhl, H. A., Kahru, M., Huffard, C. L., and Sherman, A. D.: Deep ocean communities impacted by changing climate over $24 \mathrm{y}$ in the abyssal northeast Pacific Ocean, P. Natl. Acad. Sci. USA, 110, 19838-19841, doi/10.1073/pnas.1315447110, 2013.

Stanley, R. H. R, Buesseler, K. O., Manganini, S. J., Steinberg, D. K., and Valdes, J. R.: A comparison of major and minor elemental fluxes collected in neutrally buoyant and surface-tethered sediment traps, Deep-Sea Res. Pt. I, 51, 1387-1395, 2004.

Stukel, M. R., Landry, M. R., Benitez-Nelson, C. R., and Goericke, R.: Trophic cycling and carbon export relationships in the California Current Ecosystem, Limnol. Oceanogr., 56, 1866-1878, doi:10.4319/lo.2011.56.5.1866, 2011.

Stukel, M. R., Ohman, M. D., Benitez-Nelson, C. R., and Landry, M. R.: Contributions of mesozooplankton to vertical carbon export in a coastal upwelling system, Mar. Ecol.-Prog. Ser. 491, 47-65, doi:10.3354/meps 10453, 2013.

Thunell, R. C.: Particle fluxes in a coastal upwelling zone: sediment trap results from Santa Barbara Basin, California, Deep-Sea Res. Pt. II, 8-9, 1863-1884, 1998.

Turner, J. T.: Zooplankton fecal pellets, marine snow, phytodetritus and the ocean's biological pump, Prog. Oceanogr., 130, 205-248, 2015.

Volk, T. and Hoffert, M. I.: Ocean carbon pumps: analysis of relative strengths and efficiencies in ocean-driven atmospheric $\mathrm{CO}_{2}$ changes, Geophys. Monogr., 32, 99-110, 1985.

Yao, X. and Schlitzer, R.: Assimilating water column and satellite data for marine export production estimation, Geosci. Model Dev., 6, 1575-1590, doi:10.5194/gmd-6-1575-2013, 2013. 